\title{
Business cycle research in marketing: a review and research agenda
}

\author{
Marnik G. Dekimpe ${ }^{1,2}$ - Barbara Deleersnyder ${ }^{1}$
}

Received: 31 August 2016 / Accepted: 27 April 2017 / Published online: 7 June 2017

(C) The Author(s) 2017. This article is an open access publication

\begin{abstract}
Business cycles (BCs) may affect entire markets, and significantly alter many firms' marketing activities and performance. Even though managers cannot prevent BCs from occurring, marketing research over the last 15 years has provided growing evidence that their impact on consumers, and hence on firm and brand performance, depends to a large extent on how firms adjust their marketing mix in response to these macroeconomic swings. In this study, we review the growing marketing literature on how to attenuate or amplify the impact of BC fluctuations. Our discussion focuses on three key aspects: (1) the scope of, and insights from, existing $\mathrm{BC}$ research in marketing, (2) advancements in the methods to study various BC phenomena in marketing, and (3) some emerging trends that offer new challenges and opportunities for future $\mathrm{BC}$ research in marketing.
\end{abstract}

Keywords Business cycle $\cdot$ Recession $\cdot$ Marketing conduct . Marketing strategy $\cdot$ Asymmetric behavior $\cdot$ Long-run growth

\section{Introduction}

Marketing research has long overlooked the impact of business cycle (BC) fluctuations. However, at the turn of the

Mark Houston served as Area Editor for this article.

Marnik G. Dekimpe

m.g.dekimpe@tilburguniversity.edu

Barbara Deleersnyder

b.deleersnyder@tilburguniversity.edu

1 Tilburg University, Warandelaan 2, 5000, LE

Tilburg, The Netherlands

2 KU Leuven, Leuven, Belgium twenty-first century, after more than a decade of economic prosperity, a severe contraction hit the global economy, which reminded marketers that BCs can severely disrupt business activities, and even threaten many firms' survival prospects.

An often-used definition of BCs goes back to the classic study of Burns and Mitchell (1946, p. 3), who state:

"A cycle consists of expansions occurring at about the same time in many economic activities, followed by similarly general recessions, contractions, and revivals which merge into the expansion phase of the next cycle; this sequence of changes is recurrent but not periodic; in duration business cycles vary from more than one year to ten or twelve years."

Importantly, these cycles are visible across multiple aggregate economic series such as real Gross Domestic Product (GDP), real income, or employment, among others (Stock and Watson 1999). For the U.S., the National Bureau of Economic Research's (NBER) Business Cycle Dating committee considers a broad array of economic indicators, and then decides on the location of peaks and troughs in economic activity, defining a recession as the period between a peak and a trough, and an expansion as the period between a trough and the next peak. This identification of peaks and troughs is judgmental, and open to debate. Other researchers have put forward specific rules for defining a recession based on economic aggregates. A popular definition often attributed to a 1974 New York Times article by Shiskin, for example, characterizes a recession as two or more consecutive quarters of negative GDP growth. This definition has been applied in marketing studies by, among others, Kamakura and Du (2012) and Sethuraman et al. (2011).

$\mathrm{BCs}$ have traditionally received ample attention in the economic literature, and many of the definitions and operationalizations have (not surprisingly) originated from that 
field. But unlike macro-economists' focus on the aggregate impact on entire industries and countries, marketing researchers have also been intrigued by the observation that not all firms (or brands) are affected to the same extent, nor react similarly, when faced with an economic contraction or expansion. In 2009, Reckitt Benckiser, a medium-sized British Consumer Packaged Goods (CPG) firm, reported a $14 \%$ increase in profits and an $8 \%$ increase in sales, while most of its competitors were down by more than $10 \%$ in profits (The Economist 2009). Reckitt put this down to its proactive marketing strategy to persuade its customers to still pay for its more expensive branded products, even when times got tough. To convince its customers, the firm increased its spending on marketing by $25 \%$ that year, while most of its competitors cut their marketing budgets considerably. Reckitt Benckiser is not unique. According to an eight-year study by consulting firm Bain \& Co. that analyzed the net profit margins and sales of more than 2500 companies, about $24 \%$ more firms moved from the back of the pack to a leadership position in the 2001 downturn compared with the subsequent period of economic calm. Meanwhile, about one-fifth of all leading firms - those in the top quartile in their industry based on financial performancefell to the bottom quartile in the 2001 economic downturn (The Wall Street Journal 2009). A similar heterogeneity is observed in Gulati et al. (2010). In a study across the past three global recessions, they found that $17 \%$ of the close to 5000 studied public companies did not survive the recession, while $80 \%$ of the surviving firms continued to struggle three years after the recession. Yet, almost $10 \%$ of their sample was found to flourish following the recession, doing better on key financial performance metrics than before, and outperforming their rivals in the industry by a considerable margin.

Triggered by impactful changes that force many managers to reconsider, and even turn around, their "normal" business activities, BCs (and especially economic contractions) have caught a renewed attention from marketing researchers over the last 15 years. This has resulted in a new stream of literature that provides marketing managers with guidelines on how to weather tight economic times. The aim of this article is to review existing research on $\mathrm{BCs}$ in marketing, and to point out where additional research is called for. Our discussion focuses on three key areas: (1) the scope of, and insights from, existing $\mathrm{BC}$ research in marketing, (2) advancements in the methods to study various $\mathrm{BC}$ phenomena in marketing, and (3) some emerging trends that offer new challenges and opportunities for future $\mathrm{BC}$ research in marketing.

\section{Existing $B C$ research in marketing: what have we learned?}

Historically, BCs were studied primarily in the macroeconomic literature (see, for example, Christiano and
Fitgerald 1998 or Zarnowitz 1985). However, the aggregate state of a country's national economy is not always representative of what happens at the individual industry level (Stock and Watson 1999; Berman and Pfleeger 1997), let alone at the firm or brand level, entity aggregations often studied in marketing. Before 2000, academic marketing research on the topic was scarce. In a 2005 review by Srinivasan, Rangaswamy and Lilien (p. 110), only three studies (Coulson 1979; Cundiff 1975; Yang 1964) on economic contractions were published prior to 2000 in the Journal of Marketing, the Journal of Marketing Research, or Marketing Science, with the most recent in 1979. However, since 2000, the number of marketing studies on $\mathrm{BCs}$ has grown rapidly.

An overview of 31 post- 2000 marketing studies that focus on the impact of the BC is presented in Table 1. In all studies (ordered chronologically), BCs were a key theme in the theorizing and/or empirical analysis (i.e., the state of the economy was not just included as one of the control variables). ${ }^{1}$

We organize our discussion of the main insights from these studies along the following five dimensions: (1) the key focus of the study (output metric, marketing input, or marketing-mix effectiveness), (2) the type of industry (durables, non-durables, and services, in either a B2B or B2C setting), (3) the geographic coverage (single country, multi-country, or global), (4) the data characteristics (temporal aggregation and time span) and, finally, (5) the temporary versus permanent nature of the $\mathrm{BC}$ impact. Figure 1 visualizes and structures the core research themes studied in the marketing literature so far that will be covered in this review.

\section{Study focus}

A first distinction is based on the focus of the study, where we distinguish three streams of research. A first stream focuses on how performance (=output) measures vary across the stages of the $\mathrm{BC}$, a second research stream evaluates how marketing conduct (=input) changes over the $\mathrm{BC}$, while a third one is concerned with the differential effectiveness of various marketing investments across alternative $\mathrm{BC}$ phases. In Table 2, we list the studies according to their main study focus, along with their primary research findings.

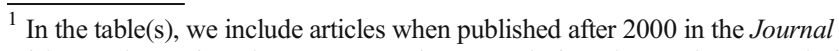
of the Academy of Marketing Science, the Journal of Marketing, the Journal of Marketing Research, Marketing Science, the International Journal of Research in Marketing, Quantitative Marketing and Economics, the Journal of Retailing, the Journal of Consumer Research, the Journal of Service Research, the European Journal of Marketing, and the Journal of Advertising. Relevant studies published in other journals (as well as working papers) are added throughout the text to complement the discussion, but are not listed in the summary tables.
} 
Table 1 Sample characteristics of empirical BC research in marketing

\begin{tabular}{|c|c|c|c|c|c|}
\hline Study & Industry & $\begin{array}{l}\text { Entity } \\
\text { aggregation }\end{array}$ & Geographic region & Time span & Temporal aggregation \\
\hline Estelami et al. (2001) & $\mathrm{B} 2 \mathrm{C}$ & brand & $\begin{array}{l}\text { mostly U.S. \& some } \\
\text { other countries }\end{array}$ & 1961-1999 & (meta-analysis) \\
\hline Grewal \& Tansuhaj (2001) & n.a. ${ }^{\mathrm{a}}$ & firm & Thailand & 1998-1999 & (cross-sectional survey) \\
\hline Deleersnyder et al. (2004) & B2C: durables & category & U.S. & $1947-2000$ & yearly \\
\hline Srinivasan et al. (2005) & $\mathrm{B} 2 \mathrm{~B}$ & firm & U.S. & 2002 & (cross-sectional survey) \\
\hline Sudhir et al. (2005) & photographic film & firm & U.S. & $1981-1998$ & quarterly \\
\hline Lamey et al. (2007) & $\mathrm{B} 2 \mathrm{C}: \mathrm{CPG}$ & category & $\begin{array}{l}\text { Belgium; U.K.; U.S.; } \\
\text { West Germany }\end{array}$ & 1971-2004 & yearly \\
\hline Deleersnyder et al. (2009) & advertising & country & 37 countries & $1980-2004$ & yearly \\
\hline Fornell et al. (2010) & national economy & country & U.S. & 1994-2008 & quarterly \\
\hline Dutt \& Padmanabhan (2011) & $\mathrm{B} 2 \mathrm{C}$ & country; category & $\begin{array}{l}99 \text { countries; } \\
54 \text { countries }\end{array}$ & $1960-2003 ; 1990-2006$ & yearly \\
\hline Graham \& Frankenberger (2011) & $\begin{array}{l}\text { B2C, B2B } \\
\quad \& \text { services }\end{array}$ & firm & U.S. & $1972-2000$ & yearly \\
\hline Ma et al. (2011) & $\mathrm{B} 2 \mathrm{C}: \mathrm{CPG}$ & category; brand & U.S. & $2006-2008$ & monthly \\
\hline Sethuraman et al. (2011) & $\mathrm{B} 2 \mathrm{C}$ & Brand & $\begin{array}{l}\text { mostly U.S. \& some } \\
\text { other countries }\end{array}$ & $1960-2008$ & (meta-analysis) \\
\hline Srinivasan et al. (2011) & $\begin{array}{l}\text { B2C, B2B } \\
\quad \& \text { services }\end{array}$ & firm & U.S. & $1969-2008$ & yearly \\
\hline Steenkamp \& Fang (2011) & multi-industry & Firm & U.S. & $1971-2005$ & yearly \\
\hline Kamakura \& Du (2012) & B2C \& services & category & U.S. & $1982-2003$ & yearly \\
\hline Lamey et al. (2012) & B2C: $\mathrm{CPG}$ & category & U.S. & $1985-2005$ & yearly \\
\hline Tuli et al. (2012) & services: retailing & firm & U.S. & $2000-2010$ & yearly \\
\hline Gordon et al. (2013) & B2C: $\mathrm{CPG}$ & category & U.S. & $2001-2006$ & quarterly \\
\hline van Heerde et al. (2013) & B2C: $\mathrm{CPG}$ & brand & U.K. & $1993-2010$ & monthly \\
\hline Yeung et al. (2013) & national economy & country & 9 European countries & 1999-2011 & yearly \\
\hline Kashmiri \& Mahajan (2014) & multi-industry & firm & U.S. & $2000-2009$ & yearly \\
\hline Kumar et al. (2014) & services: airline & consumer & U.S. & $2008-2011$ & (longitudinal survey) \\
\hline Lamey (2014) & B2C: $\mathrm{CPG}$ & category & 15 European countries & 1991-2008 & yearly \\
\hline Ou et al. (2014) & services: various & firm & the Netherlands & 2010 & (cross-sectional survey) \\
\hline Özturan et al. (2014) & $\mathrm{B} 2 \mathrm{C} \& \mathrm{~B} 2 \mathrm{~B}$ & firm & Turkey & 2002 & (cross-sectional survey) \\
\hline Hunneman et al. (2015) & services: retailing & firm (retailer) & the Netherlands & 2009-2012 & monthly \\
\hline Dekimpe et al. (2016) & services: tourism & category & 30 countries & $1980-2013$ & yearly \\
\hline Dhar \& Weinberg (2016) & services: movies & brand (movie) & U.S. & $1983-2009$ & weekly \\
\hline Edeling \& Fischer (2016) & multi-industry & firm & $\begin{array}{l}\text { mostly U.S. \& some } \\
\text { other countries }\end{array}$ & $1971-2011$ & (meta-analysis) \\
\hline Dubé et al. (2017) & B2C: $\mathrm{CPG}$ & consumer & U.S. & 2004-2012 & monthly \\
\hline Peers et al. (2017) & services: tourism & category & 18 countries & $1981-2011$ & yearly \\
\hline
\end{tabular}

${ }^{\mathrm{a}}$ n.a. = not available

\section{Focus on performance (output)}

Several studies (see panel A of Table 2) have evaluated the impact of BCs on a variety of performance measures. These studies often consider not only the extent of cyclical sensitivity in a particular industry or category, but also whether the resulting cyclical fluctuations are symmetric.

Extent Studies often compare the cyclical fluctuations in the variable of interest with those in the overall economy, and consider (1) whether they occur in the same (pro-cyclical) or opposite (counter-cyclical) direction and (2) whether they get amplified or attenuated relative to those in the economy as a whole. Deleersnyder et al. (2004), for example, show that consumer durables in the U.S. are very sensitive to BCs, with cyclical fluctuations that are, on average, more than four times larger than (but in the same direction as) those in GNP. Similarly, Dekimpe et al. (2016) find an excess sensitivity to economic cycles in the international tourism sector, while Cleeren et al. (2015) show that also expenditures on health 


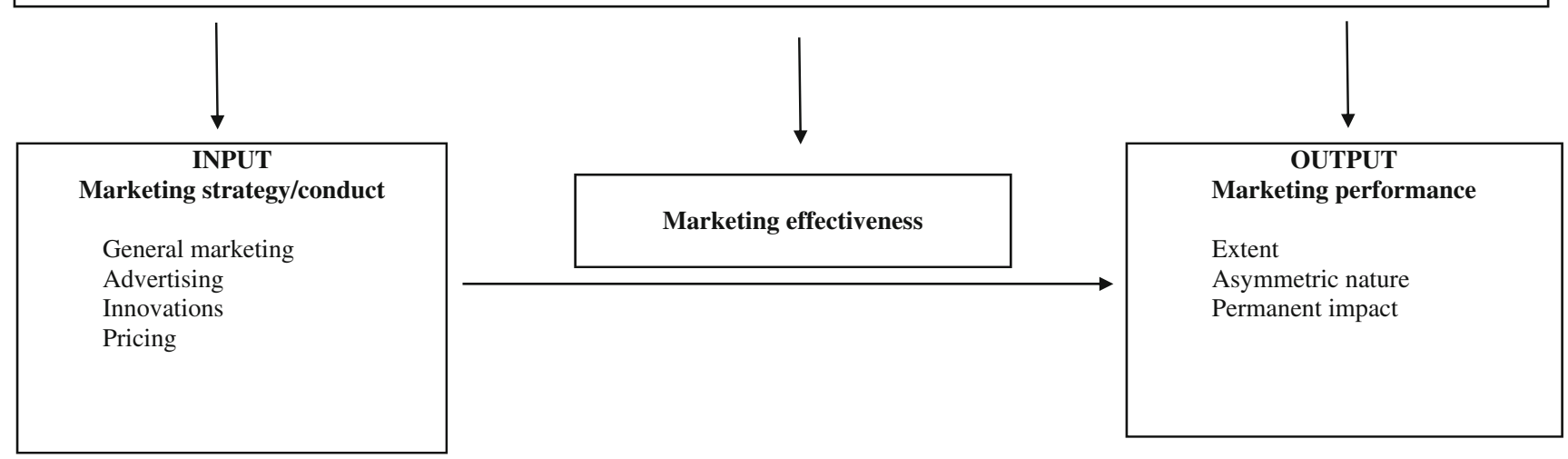

\section{Research setting:}

Industry: durables vs. non-durables -B2B vs.B2C -goods vs.services

Geography: US - Europe -Asia - Emerging markets

Data: time span - level of temporal aggregation

Fig. 1 Overview of $\mathrm{BC}$ research in marketing

care are affected by aggregate economic fluctuations, as people save on their private healthcare spending during adverse economic conditions. The latter adjustments are, on average, less pronounced than in other economic sectors, even though there is considerable heterogeneity across countries. Governmental or public spending on healthcare, on the other hand, is much less affected by cyclical ups and downs, in order to assure a continued healthcare service irrespective of the state of the economy. In terms of movie demand, Mukherjee and Xiao (2016) find that while overall demand for movies decreases, the demand for escapist movies increases, a conclusion similar to the findings of Dhar and Weinberg (2016).

Other studies focus more on how consumers re-allocate their budgets, rather than on the absolute size of the up- or downswings. Dutt and Padmanabhan (2011), Millet et al. (2012) and Kamakura and Du (2012) show in this respect how macro-economic conditions instigate consumers to shift their spending across product categories and time. Dutt and Padmanabhan (2011) describe how, in a monetary crisis, consumers smooth their consumption at various levels: they shift spending over time and between different types of durable goods, non-durable goods and services. Millet et al. (2012) illustrate how consumers shift their spending during economic contractions towards products or services associated with avoiding negative outcomes (such as insurances), while products associated with achieving positive outcomes (e.g., gambling) are more popular during good economic times. Kamakura and $\mathrm{Du}$ (2012), in turn, show a shift in consumption from positional (status-conveying) goods and services to non-positional ones during recessions, and from discretionary to more necessary products, even if the total consumer budget is unaffected.

Finally, apart from economizing on total spending or instead of shifting spending across product categories, research has also shown how, especially for necessary goods, consumers reduce their spending during contractions by switching to less expensive brands within the category. Lamey et al. (2007), for instance, were the first to show (across four different countries) that many consumers switch to cheaper store brands during their grocery shopping in bad economic times, while they switch (albeit not fully) back to national brands in the subsequent recovery. The same conclusion is echoed in Dubé et al. (2017), even though they posit that the switch to private labels due to income and/or wealth shifts is less extreme than reported in Lamey et al. (2007) and Lamey et al. (2012). Dekimpe et al. (2011) and Lamey (2014) argue that observed increases in store brand sales are partly due to consumers shopping more at discounters during bad economic times where only few national brands are offered, "forcing" consumers to choose among the less expensive store brand alternatives. Switching to cheaper brands allows consumers to reduce total spending without having to give in on the amount consumed. Ma et al. (2011), in turn, focus on the price of gasoline, a macro-economic factor that is changing more rapidly than $\mathrm{BCs}$, but which also causes consumers to make adjustments in their buying patterns. When gasoline prices rise sharply, consumers have less disposable income, and must find ways to reduce spending in other areas. This study examines and finds various potential avenues for savings in consumer grocery spending: shopping frequency is reduced and shifts towards supercenter retail formats, from 


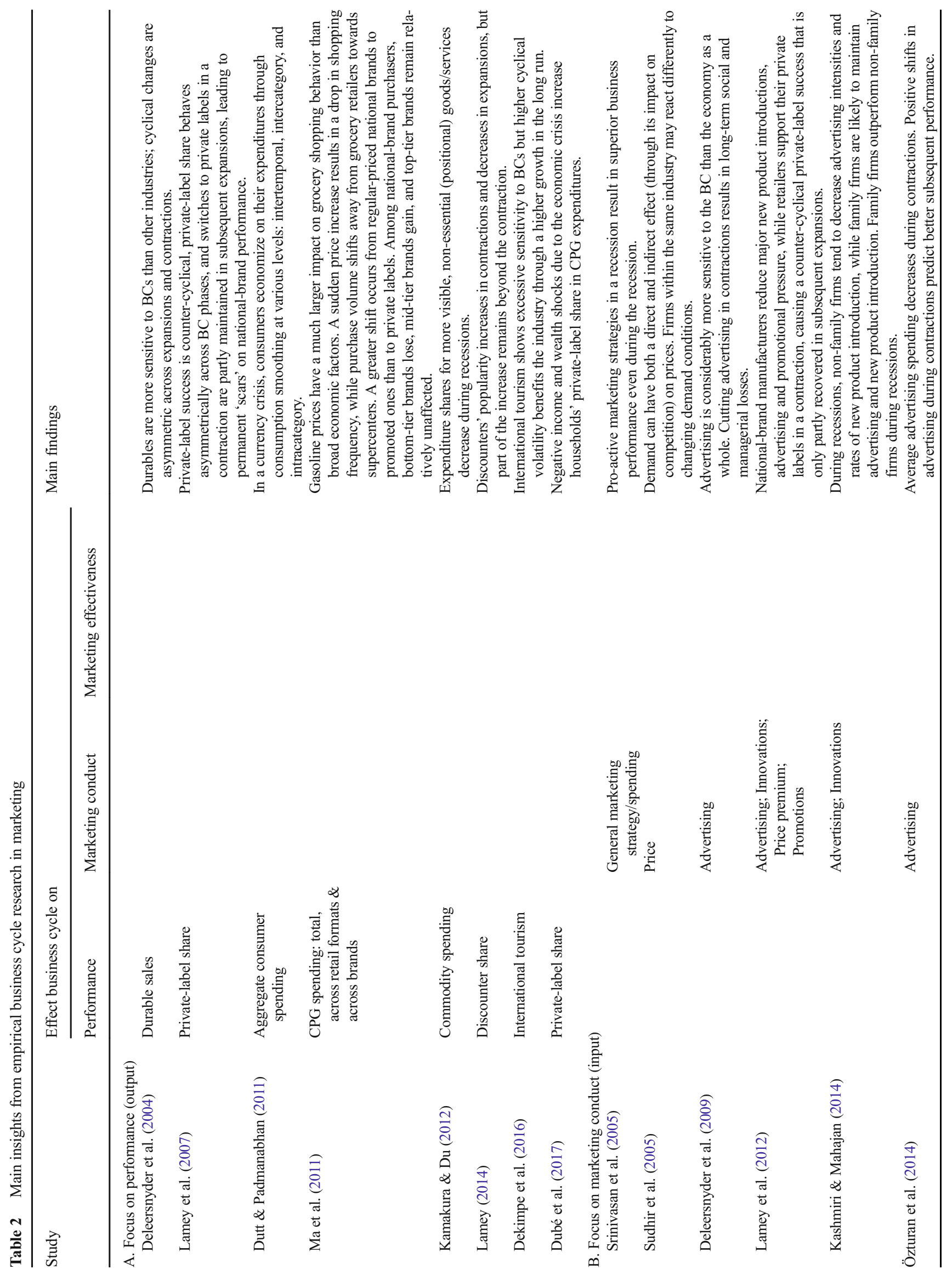




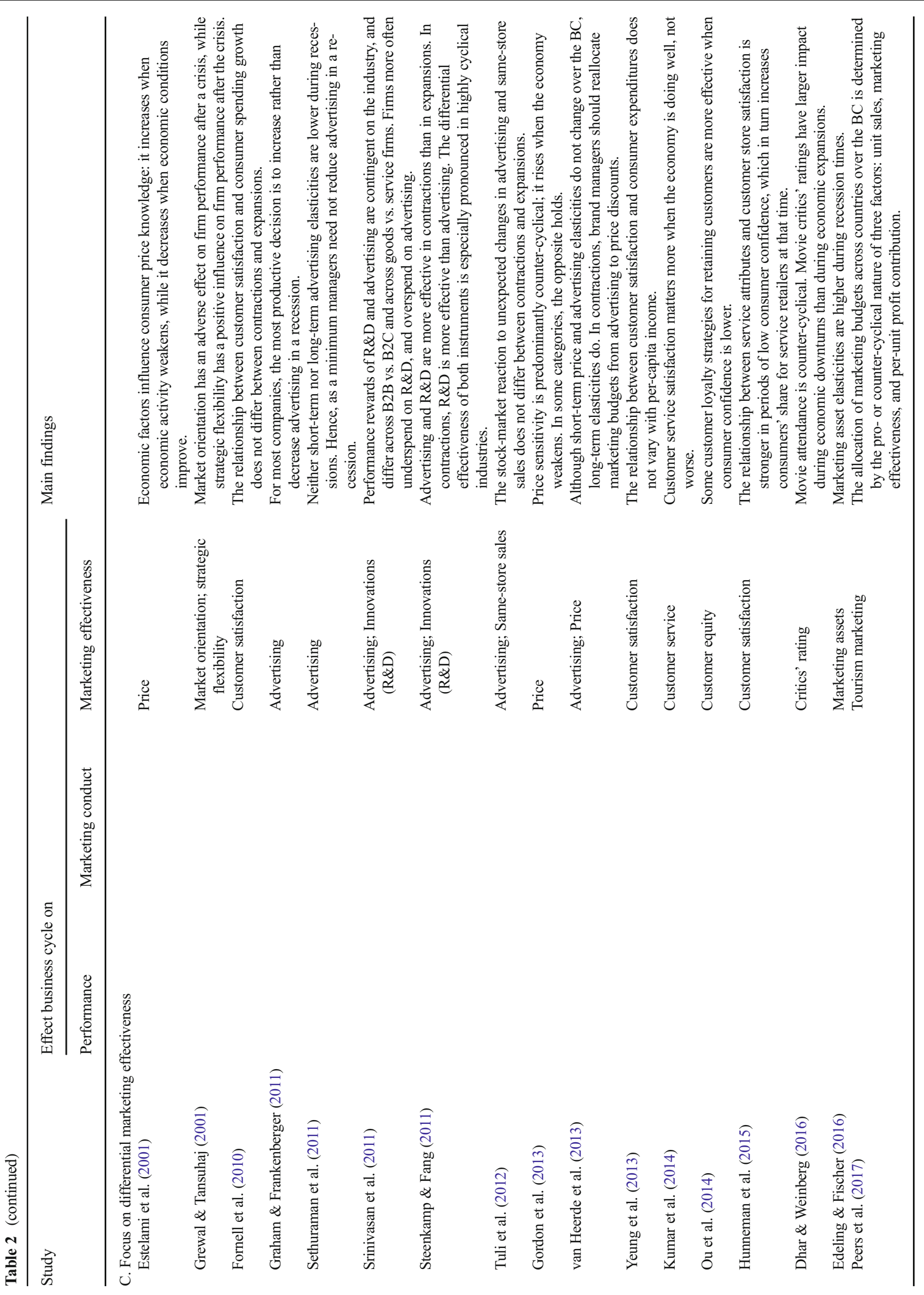


national brands to private labels, and from regular-priced to promotional products. Relatedly, Cha et al. (2015) show that household coping strategies for food purchases are not restricted to switching to less expensive brand alternatives or cheaper store outlets, but also that more items will be sold on deal when the economy turns sour.

Future research While previous research has documented the possibility of multiple coping strategies, little is known about their relative occurrence. What are the categories where consumers opt to consume less, under what circumstances do they switch to cheaper alternatives, and for what products do they intensify their search to still buy the same brand either in a cheaper retail outlet or on deal? And how (and why) does this choice of coping strategy vary across consumer segments. Most prior studies have taken a fairly aggregate point of view, and focused, for example, on country-level durable sales, total category sales, or overall private-label shares. More research is needed to determine which consumers are more reluctant to adjust their consumption behavior when the economic conditions deteriorate, and opt instead to incur additional debt to maintain as long as possible their pre-crisis consumption standards. Similarly, future research should identify what firms (smaller/larger, publicly-listed versus family-owned, etc.) are more/less likely to suffer (or prosper) during difficult economic times, and/or what brands (e.g., global versus local, with more or less sub-brands) are more resistant to cyclical fluctuations.

Asymmetric nature Apart from the size and direction of the $\mathrm{BC}$ fluctuations in performance, a number of studies in this research stream have documented asymmetries between upand downward movements in category or industry performance. This is observed in durable sales by Deleersnyder et al. (2004), but also private-label performance (Lamey et al. 2007) exhibits cyclical up- and downward movements that are not mirror images. In tourism, Dekimpe et al. (2016) examined, but could not find, such asymmetries across alternative BC phases. Asymmetries can occur in both the speed and depth of the cyclical fluctuations.

In Deleersnyder et al. (2004), consumers are found to cut back more (= depth) and faster (= speed) on their durable purchases during contractions than they increase spending in subsequent expansion periods. Asymmetries in the speed of downward versus upward adjustments, or steepness asymmetry, may arise from the way consumers gain (slow) or lose (fast) trust in the economic climate (Nooteboom et al., 1997). Moreover, people find themselves at the lowest level of their income right after a recession, so any initial rise in income will be used first to pay off debts and/or rebuild a precautionary stock of assets or capital (Gale 1996; Carroll 1992). Consequently, consumers are quick in cutting back on their durable expenditures in a contraction, while upward adjustments after the contraction are more slowly. As such, it takes considerably more time to restore the initial consumer spending. Dekimpe et al. (2016) could not find any systematic asymmetry in the speed of adjustment in tourism demand across contractions and expansions, suggesting a quicker recovery than many other (nonservice) sectors.

Asymmetries also arise in the size of the peaks and troughs of durable sales, causing the troughs to be deeper (relative to the mean level) than the peaks are tall, a phenomenon sometimes referred to as deepness asymmetry. A rationale for this can be found in prospect theory (Tversky and Kahneman 1991), which posits that people react more extensively to unfavorable changes than to comparable gains. If households experience or expect a deterioration in their wages or income, they considerably reduce their spending levels, especially for more discretionary products, while upward adjustments during expansions trigger more moderate reactions (Deleersnyder et al. 2004). Evidence of comparable asymmetries with CPG products is given in Lamey et al. (2007), where consumers are found to switch quickly and extensively towards private labels in contractions, while their switching back to national brands in the subsequent expansion period occurs more slowly and less extensively.

Future research First, more studies have documented on the extent of cyclical sensitivity than on the cyclical asymmetry in performance series. As such, little is known on possible contingency factors for, respectively, level and speed asymmetries. It would be useful to consistently report on both asymmetry dimensions. Second, it would be interesting to further explore the temporal dimension in the reported asymmetries. For example, does a higher speed of adjustment take place primarily during the initial months of the contraction, after which some habituation takes place? And how about the frugal fatigue discussed in ter Braak et al. (2014)? Do customers re-evaluate and adjust their coping behavior when the contraction lingers on for too long? Importantly, more research is also needed into the underlying psychological motivations of both consumers and managers to better understand why these asymmetric patterns are observed (or not).

\section{Focus on marketing conduct (input)}

The extent of BC fluctuations in various marketing input series has been evaluated in several studies (see Panel B of Table 2) that assess whether and how managers adjust their marketing actions in response to, respectively, adverse and prosperous economic times.

General marketing One of the first studies in this area was Srinivasan et al. (2005), who show empirically that a recession presents a unique opportunity for firms to strengthen their market position by going against the tide 
with a "proactive marketing strategy." Based on management survey data, they show that firms with a strategic emphasis on marketing during the recession achieve superior business performance. The study is concerned with general marketing spending, without distinguishing between different marketing investments. In later studies, researchers also examined individual marketing instruments.

Advertising Studies on the extent of advertising spending over the BC cycle have repeatedly shown that a majority of firms cuts back significantly on advertising in a contraction, while advertising spending rebounds in the subsequent expansion period (Deleersnyder et al., 2009; Kashmiri and Mahajan 2014; Lamey et al. 2012; Özturan et al., 2014). Deleersnyder et al. (2009), for example, document pro-cyclical advertising adjustments across 37 countries worldwide in four traditional media (TV, radio, newspapers, and magazines). Various reasons have been advanced to explain why general $\mathrm{BC}$ swings become amplified in advertising expenditures. These include the widely held view of advertising as a cost rather than an investment, the low commitment to and flexibility in media contracts, and the fact that fewer competitors engage in advertising in recessionary times, which warrants a lower spending level to achieve the same share-of-voice (Deleersnyder et al. 2009). In addition, herding behavior can lead to further reductions once some firms start to cut their spending (Steenkamp and Fang 2011).

Despite the dominant practice of cutting back on advertising, research has repeatedly shown that maintained, or even increased, advertising spending during economic contractions often results in long-term managerial and social benefits, which can be in the form of better firm performance (Deleersnyder et al. 2009; Özturan et al. 2014; Kashmiri and Mahajan, 2014), lower long-term private-label growth (Deleersnyder et al. 2009; Lamey et al. 2012), and higher long-term growth of the advertising industry itself (Deleersnyder et al. 2009).

Innovations Research in both economics and marketing shows that innovation development and new-product launches exhibit pro-cyclical adjustment patterns, i.e., they move in the same direction as the general economy (see, e.g., Devinney 1990; Axarloglou 2003; Barlevy 2007; Lamey et al. 2012; Kashmiri and Mahajan 2014). According to Lamey et al. (2012), BC fluctuations in this instrument get amplified, both for major and more incremental innovations. The arguments for the more severe reductions in spending on innovations and $R \& D$ are similar to those for reduced advertising, and relate to difficult spending justification, its common treatment as a suspendable cost, and a reduction in the number of competing innovations. In this context, Kashmiri and Mahajan (2014) show that the reduction in the rate of new-product introductions is less dramatic in family- owned firms, given the longer investment horizon of family executives. Both Lamey et al. (2012) and Kashmiri and Mahajan (2014) show that if managers maintain or increase new product introductions in a recession, they will achieve higher growth and better (long-term) performance than when they systematically cut such activities, albeit temporarily, in response to adverse economic shocks.

Price In economics, opposing arguments on the direction of the recommended price changes during economic contractions have been made. On the one hand, it has been argued that prices should decrease when demand is unexpectedly low. Firms then switch from collusive higher prices to lower competitive prices, because they attribute their lower demand to cheating on the part of their rivals (see, e.g., Green and Porter 1984). On the other hand, it has also been argued that especially during high-demand periods (or booms), it is more beneficial to undercut the higher collusive prices (see, e.g., Rotemberg and Saloner 1986). Others have studied the implications of demand trends on competition. For example, Haltiwanger and Harrington (1991) argue that the threat of future punishments is a stronger deterrent if demand is increasing versus decreasing. Thus, firms are more likely to sustain higher (collusive) prices when the demand trend is positive. An in-depth discussion on the differences between these models is provided in Sudhir et al. (2005), who introduce the notion of time-varying competition (with the extent of competition a function of aggregate demand). They discuss how demand can have both a direct effect on prices, and an indirect effect through changing competition. Marn et al. (2003), in turn, point out that managers have a tendency to increase prices ( $\mathrm{p}$ ) during a contraction to offset the revenue $\left(p^{*} q\right)$ losses caused by reduced sales ( $q$ ) levels.

Deleersnyder et al. (2004), studying 24 consumerdurable categories, find evidence of counter-cyclical pricing: prices tend to increase during an economic contraction, and to decrease during an expansion. This, in turn, contributed significantly to the resulting amplified cyclical sensitivity in category sales. Sudhir et al. (2005) allow for firm-specific adjustments, and show how, in the U.S. photographic film market, Kodak priced more competitively in periods of high demand (reflected in higher levels of consumer confidence), while Fuji did not respond to changes in consumer confidence. Also Gilchrist et al. (2015) observe differences in firms' price-setting behavior in response to adverse demand, which they attribute to differences in the firms' liquidity position.

Lamey et al. (2012) document clear cyclical patterns in various promotional activities in the CPG industry. The relative intensity of national-brands' promotions compared to private labels was found to decrease during economic downturns for three main promotion instruments (displays, features, and temporary price cuts), while the reverse pattern is observed in 
expansions. Importantly, unlike advertising and innovations, the promotional instrument is a shared manufacturer-retailer decision, with the retailer having the final say. So the observed decline in relative promotion activity may be caused by manufacturers cutting back on promotions in a recession, by retailers reducing the pass-through during that time, or a combination of both. The regular price premium of branded offerings over private-label variants is the only marketing instrument in Lamey et al. (2012) with no clear adjustment pattern following changes in the state of the economy. Also Coibion et al. (2015) find little cyclical sensitivity in the inflation rate of prices posted by grocery retailers. However, they find that there is more cyclical sensitivity in the effective prices paid by consumers, consistent with consumers reallocating their expenditures to lower-priced brands and stores when local economic conditions deteriorate.

Future research First, existing studies have almost exclusively focused on the cyclical sensitivity in one or two traditional marketing instruments. It would be good to move beyond the often-studied price and advertising variables, and to also consider variables such as assortment composition, distribution intensity, or online marketing activities that have not yet been studied (as extensively) in a BC context. For example, to what extent do (or should) national-brand manufacturers offer cheaper versions (e.g., Tide Basic) of their premium brand during recessions (similar to retailers offering multiple private-label tiers), or offer different (e.g., smaller) package sizes, and how can they do so without undermining the postrecession equity of their original brand? Similarly, should national-brand manufacturers try to get their product listed with hard discounters during economic downturns to maintain their overall sales levels, or will this undermine their relationships with their traditional channel partners (see also Dekimpe et al. 2011 for a more detailed discussion on these issues), which could hurt their performance in the subsequent expansion? And how about retailers? To what extent is the optimal proportion of private-label SKUs in their assortment (see, for example, Ailawadi et al., 2008) dependent on the state of the economy? And how should this number be divided across the different private-label tiers (budget, regular, premium)?

Second, it would be useful to consider marketing instruments at a lower level of aggregation. For example, it is customary to talk about the reduction in aggregate advertising spending in recessionary times. However, does this also apply to the many new online instruments? Due to its increased flexibility, cost effectiveness, better targeting opportunities, and improved measurability, one could argue that internet advertising is ideally suited for times where budgets are constrained, and where each marketing initiative needs to be justified extensively (Quelch and Jocz 2009). More research is needed to see whether the cyclical swings in online spending will be even more pronounced, or whether online advertising (and sales) is more resilient. Future research should examine this empirically for the growing set of online marketing instruments and channels.

Finally, little is known to what extent the content of the ads is (should be) adjusted. Similarly, should the type of innovations be tailored to worsening (improving) economic conditions?

\section{Focus on differential marketing effectiveness}

Finally, various studies (see Panel C of Table 2) have evaluated how the effectiveness of different marketing actions changes when the economy deteriorates/improves. If this is the case, managers are often recommended (see, e.g., Steenkamp and Fang 2011; van Heerde et al., 2013) to shift their spending from periods with lower marketing effectiveness to periods characterized by a higher effectiveness. Thus far, studies have mainly looked at this issue in the context of advertising, R\&D, and prices, even though evidence also exists for a differential importance over the $\mathrm{BC}$ of customer satisfaction (Hunneman et al., 2015; Kumar et al., 2014; Ou et al., 2014) and of critics' ratings of movies (Dhar and Weinberg 2016).

R\&D investments and pricing Overall, research findings are consistent with respect to R\&D investments and pricing: for the majority of products and brands, both instruments are more effective in economic downturns, and hence, it is recommended to increase the spending on $R \& D$ and to focus more on price reductions during an economic downturn. These conclusions are based on studies by, among others, Srinivasan et al. (2011) and Steenkamp and Fang (2011) for R\&D spending, and Estelami et al. (2001), Gordon et al. (2013) and van Heerde et al. (2013) for prices. In addition, Schöler et al. (2014) find that the riskiness and radicalness of financial innovations tends to increase the introducing banks' abnormal returns, even though radicalness has lower cumulative abnormal stock returns in recessions than in expansions. No such interaction was found for riskiness.

Advertising Research findings are less equivocal for advertising. Srinivasan et al. (2011) show, across many industries, that firms, from a profit point of view, tend to overspend on advertising in a recession, while van Heerde et al. (2013) find that long-term advertising elasticities are lower in a recession, suggesting that advertising should be reduced during that time. In contrast, a higher advertising effectiveness is found in Steenkamp and Fang (2011) and Graham and Frankenberger (2011), leading them to recommend higher advertising spending in a recession. The same recommendation is provided by studies that linked the cyclical fluctuations in advertising to long-term firm performance, such as Deleersnyder et al. (2009) or Lamey et al. (2012). In a recent meta-analysis, Edeling and Fischer (2016) look at the stockmarket impact of both current advertising expenditures (a flow 
variable) and market assets (stock variables, which can be brand related, like brand equity, or customer related, like customer equity). They find the marketing-asset elasticities to be higher during recession times (while no such effect was found for advertising expenditure elasticities). Strong assets help firms to retain customers and thus attenuate the negative financial consequences of recessions. Given that marketing assets are quite sticky, however, one could make a case to try to increase the asset already in better times, when more financial resources may be available.

Customer satisfaction and movie critics Also other marketing activities have been shown to have a differential effectiveness across alternative BC stages. Several papers have shown that the impact of/on customer satisfaction changes when the economy deteriorates. Hunneman et al. (2015), for instance, examine the relationship between customer satisfaction with the retailer and consumers' share of wallet during grocery shopping. While this relationship is not directly moderated by consumer confidence, the impact of service attributes on customer satisfaction is stronger in periods of low consumer confidence, making consumers spend more at higher service firms when the economy is down. Similarly, Ou et al. (2014) examine the moderating role of consumer confidence on the relationship between various customer equity drivers (value equity, brand equity and relationship equity) and consumer loyalty intentions. The differential effectiveness across high and low consumer confidence varies across industries. Also, according to Kumar et al. (2014), the returns on marketing investments in customer satisfaction in the airline service industry differ between expansions and contractions. Unlike earlier expectations, investments in service satisfaction are found to be more effective in expansion periods. Finally, Dhar and Weinberg (2016) find that movie critics have a higher impact on movie demand in contractions.

However, not all marketing relationships have been found to differ between expansion and contraction periods. For example, Tuli et al. (2012) did not find an asymmetric stock-market reaction to unexpected changes in advertising spending and growth in same-store sales, and Fornell et al. (2010) found the relationship between customer satisfaction and consumer spending growth to not change structurally in the recent great financial crisis. A similar conclusion was obtained in Yeung et al. (2013), who found no significant interaction between customer satisfaction and a continuous (rather than the discrete recession dummy used in Fornell et al. 2010) income per capita metric. Van Heerde et al. (2013), in turn, found that short-run price and advertising elasticities do not change with the $\mathrm{BC}$, while their long-run counterparts do in an asymmetric way.

Future research While previous results hold for the majority of firms and brands, several studies have pointed out that there can be considerable heterogeneity depending on the industry type (Srinivasan et al. 2011; Steenkamp and Fang 2011), product category (Gordon et al. 2013; van Heerde et al. 2013), and even across different brands or firms within the category (Mukherjee and Bonfrer 2015; van Heerde et al. 2013). More research is needed to develop adequate contingency frameworks to better understand this heterogeneity in the cyclical sensitivity of marketing's effectiveness. Relatedly, more attention on qualitative issues is warranted, such as the quality of the advertising campaigns, to complement the more quantity-oriented metrics studied thus far. Will only the best creative talent be retained by advertising agencies in recessionary times, resulting in a higher average quality (and hence, more effective) campaigns running during such times?

Importantly, there is agreement across multiple studies that while individual firms or managers may not be able to prevent economic downturns from happening, they can, to some extent, limit the impact of such contractions on their performance by spending more (or refrain from cutting back, which will often improve already their relative position) on marketing during difficult times. Such a practice is sometimes referred to as proactive marketing (Srinivasan et al. 2005). Interestingly, this ability to moderate the impact of BC fluctuations allows one to partially endogenize the $\mathrm{BC}$ concept (see in this respect also Bharadwaj et al., 2005). More research is needed to better advise managers how to do this depending on their specific setting.

Clearly, many marketers do not have extra money available when times turn sour, and may therefore find this advice to invest more in marketing impractical. However, research on this issue not just argues that managers should spend more on marketing, they also make a case for spending existing budgets more smartly by shifting some of the marketing expenses on e.g., advertising, innovations, and promotions over time towards contraction periods to be able to weather tough economic times. Alternatively, one could reallocate marketing budgets across instruments (Lamey et al. 2012) or across countries (Dekimpe et al. 2016) to better ride the economic tides without increasing the total marketing budget. More research is required to make these normative recommendations, which are thus far mostly directional in nature, more actionable/concrete.

\section{Type of industry}

The impact of BCs has been found to differ between durable and non-durable industries, between B2B and B2C markets, and between purchases of goods and services.

\section{Durable vs. non-durable consumer goods}

Consumer spending on durable goods is hit particularly hard by contractions, resulting in cyclical fluctuations that are much more pronounced than those in aggregate GDP 
(Deleersnyder et al. 2004). These outlays are often a consumer choice for which there is no pressing need to make the purchase at a particular time. Consumers who want to restrict their purchases during an economic contraction tend to first reconsider these more discretionary expenditures. When faced with adverse economic conditions, consumers can postpone the acquisition (Cook 1999), and current owners of consumer durables can extend the lives of their products by repairing, rather than replacing, them (Clark et al., 1984).

In contrast, it is more difficult to cut back on non-durable consumer goods. Many frequently-purchased CPGs are seen as necessities, and their purchases have become more habitual. Because of that, the quantity bought of these products is more difficult to adjust (Lamey et al. 2007). During a contraction, consumers do not necessarily buy less of these products, but are more likely to use other strategies to economize on their spending, such as switching to cheaper alternatives (Lamey et al. 2007, 2012; Dubé et al. 2017), switching to cheaper stores like discounters (Lamey 2014) or supercenters (Ma et al. 2011), or looking for products on deal (Cha et al. 2015; Ma et al. 2011).

\section{$B 2 B$ vs. B2C industries}

Most empirical studies have focused on (durable and nondurable) consumer goods (B2C), where consumers are the final buyers. Far less attention has been devoted to the business-to-business (B2B) market (not unlike the marketing literature at large; see Lilien 2016). Notable exceptions are Özturan et al. (2014), Srinivasan et al. $(2005,2011)$ and Frösén et al. (2016). Even though one could argue that clients in B2B industries may be more rational (Srinivasan et al. 2011), and therefore less affected by short-term economicsentiment swings than end consumers, they may suffer from a "bullwhip" effect, in that small BC-induced changes in demand by the end consumer get amplified as one moves further up the supply chain (Hanssens 1998; Lee et al., 1997, 2004). Moreover, given that the resources controlled by one firm can, directly or indirectly, depend on the resources controlled by other firms in a B2B network (Andersson and Mattsson 2010), the herding effect may also get amplified. As such, the overall cyclical sensitivity could be more or less pronounced in B2B markets.

Srinivasan et al. (2005) surveyed 20 senior marketing executives from four primary industry groups (engineering, computers, telecommunications and light manufacturing). Firms that adopted a proactive marketing response during a recession are found to achieve superior performance, already during the recession. However, they did not formally examine the difference in BC impact between B2B and B2C firms. In the 2001 contraction, Özturan et al. (2014) find significantly higher cuts in advertising in Turkish B2B firms compared to B2C firms, even though firm performance in the contraction did not differ significantly between both groups. Finally, Srinivasan et al. (2011) looked into differences in spending on R\&D and advertising between both industries. They find that B2B firms are more often at a right level of advertising and R\&D spending compared to B2C firms, which often underspend on R\&D and overspend on advertising during recessions.

Frösén et al. (2016) surveyed 140 Finish B2B firms during both an economic up- and downturn, and assessed the impact of different forms of market orientation (MO) across the two economic states. The impact of the firms' MO changed during a downturn, with interfunctional coordination boosting performance, and competitor orientation becoming detrimental. Interestingly, the performance impact of customer orientation remained unaltered between the two times of measurement. Hence, different MO dimensions yield diverse performance effects depending on the state of the economy.

\section{Goods vs. services}

While manufacturers of goods can smooth production and employment through stock building and producing for inventory when demand falls in a downturn, this is not possible for services (Zeithaml et al., 1985). The inseparability of production and consumption, along with the inherent perishability of services, is likely to make them more vulnerable to $\mathrm{BC}$ swings than goods.

Kumar et al. (2014) and Dekimpe et al. (2016) both find that the state of the economy significantly influences the travel service industry. Kumar et al. (2014) show that consumers book flights less often, and spend less on travel, when the economy turns sour. Dekimpe et al. (2016) find that the New Zealand tourism industry exhibits $\mathrm{BC}$ fluctuations that exceed the swings in aggregate GDP. Spending on leisure and business trips are discretionary expenditures that are easy to postpone, and holidays are considered a luxury good that consumers scale back drastically when their income deteriorates. Apart from the more luxury spending on holiday and travel services, also spending on medical services has been subjected to a $\mathrm{BC}$ analysis. While medical needs should not fluctuate with the BC, Cleeren et al. (2015) show that especially private health-care spending changes systematically with cyclical ups or downs. Finally, services are also subject to significant influences from changes in consumer confidence through its impact on customer satisfaction with the service providers (Hunneman et al. 2015; Ou et al. 2014).

A formal comparison of the effect of changes in R\&D and advertising in a recession between goods and services was conducted in Srinivasan et al. (2011). They find that, in a recession, most $\mathrm{B} 2 \mathrm{C}$ goods firms underspend on $\mathrm{R} \& \mathrm{D}$, while they are at approximately the right level of advertising. B2C service firms, in turn, overspend on advertising during such times. Finally, B2B service firms are at approximately the right levels of $R \& D$ and advertising in a recession. These 
conclusions are based on a marginal profit analysis. However, these findings are found to differ depending on the outcome metric (profits or stock returns) that is used.

In combination, these findings show that, compared to goods firms, service firms may be affected differently by BC fluctuations, and therefore deserve separate research attention, especially since the service industry contributes significantly to most countries' GDP.

\section{Future research}

While previous research has established clear differences between the broad B2C/B2B/service typologies, it would be good to explore in more detail the heterogeneity within a given sector. For example, different services can be more or less discretionary, more or less difficult to postpone, characterized by a different income elasticity, or be more or less sensitive to social-visibility considerations (Dekimpe et al. 2016). Because of this, extrapolations from a single service sector (as tourism, which was studied in several papers), or comparisons across broad aggregates (as services vs. consumer durables vs. CPGs) may well be misleading. Similar differences within the $\mathrm{B} 2 \mathrm{C}$ and $\mathrm{B} 2 \mathrm{~B}$ sector have remained largely unexplored in the current literature. Finally, since service evaluations are highly dependent on consumers' prior expectations about the service quality, examining if and how such expectations evolve in relation to the aggregate economic activity could be worth exploring further. Similarly, the extent to which firms rely on closer and more personal relationships in a B2B industry could affect their resilience to economic adversity. Future research should explore in more detail underlying drivers of differences in $\mathrm{BC}$ sensitivity across firms and industries.

\section{Geographic coverage}

All but one study in Table 1 work at the country level when assessing the general state of the economy. However, as pointed out by Kumar et al. (2014), regional economic differences may exist within a country or market (see also Croux et al., 2001 for a similar argument), which could also have a profound effect on firm performance. In many instances, information on a less aggregate level than the country level is missing, however.

Many studies have relied on U.S. data. ${ }^{2}$ This could be attributed in part to the fact that more extensive, and especially longer, data on marketing conduct and performance are available for U.S.-based firms, and/or to the clear, publicly

\footnotetext{
$\overline{2}$ This U.S. bias is not only observed in BC research, but in the marketing literature at large (Steenkamp 2005; Burgess and Steenkamp 2006). In the meta-analysis by Estelami et al. (2001) on the relation between the macro economy and consumer price sensitivity, for instance, $80 \%$ of the 297 studies were conducted in the U.S.
}

available, delineation of contraction and expansion periods by the NBER Business Cycle Dating Committee. ${ }^{3}$ Still, it is important to extend this literature beyond the impact of the U.S. BC, as (1) economic contractions are not equally severe in all countries and may not even hit certain countries at all (Ang et al., 2000), (2) the timing of the peaks and troughs does not always coincide (Baxter and Kouparitsas 2005), while (3) also the marketing implications have been found to differ between countries and cultures (see, for example, Deleersnyder et al., 2009).

Several studies have observed stark differences between countries in terms of the evolution of their BC. The 1997 Asian crisis, for instance, had a dramatic impact on the Asian markets, but its impact on Western-European countries was negligible (Ang et al. 2000; Grewal and Tansuhaj 2001). Even though important international interdependencies exist across economic markets worldwide (Baxter and Kouparitsas 2005), and even though certain shocks can hit the economic activity globally, there is increasing evidence that BCs are not always synchronized, neither with the U.S. economy, nor with the economy of neighboring countries (Cerqueira, 2013). Peers et al. (2017) observe in this respect how the "global" financial crisis in 2009-2010 caused a deep trough in countries such as the U.S., the U.K., and Japan, but hardly affected China and Australia. For these countries, downturns were much more pronounced in the eighties and nineties. Also the timing of the peaks and troughs is not entirely synced. For instance, Japan went through a deep downturn in 19931995, whereas Australia experienced a strong upturn that time. The correlations between the 30 BCs in Peers et al. (2017) range from 0.90 (Malaysia-Thailand) to -0.23 (U.S. Indonesia), with an average correlation of 0.36 , well below unity. When cyclical fluctuations across countries do not coincide, multinational firms can exploit these differences, and shift marketing funds across countries that are in a different economic state. Such diversification opportunities can help to smooth the overall cyclical fluctuations in performance, and reduce the firm's cyclical sensitivity (Dekimpe et al. 2016; Peers et al. 2017).

\section{Future research}

Given differences in the strength and timing of BCs across countries, it is important to study BC phenomena beyond the often-used U.S. setting. Fortunately, a number of studies have already focused on other countries, such as Finland (Frösén et al. 2016), Turkey (Özturan et al. 2014), Thailand (Grewal and Tansuhaj 2001), the Netherlands (Hunneman et al. 2015; Ou et al. 2014), or the U.K. (van Heerde et al. 2013). Also, a few studies (see Table 1 for more details) have used data from

\footnotetext{
${ }^{3}$ Available at: http://www.nber.org/cycles.html (see also the sub-section "Discrete classification by economic institutions").
} 
multiple countries (e.g., Lamey et al. 2007), sometimes from different continents (e.g., Deleersnyder et al. 2009). The latter studied cross-country differences in the cyclical sensitivity of advertising spending. Data across 37 countries revealed significant differences in the extent that advertising is reduced during contractions, which could be partly attributed to cultural differences between the countries. Still, the number of truly cross-national studies is limited. It would be useful to expand the geographic scope of the studies to include more developing economies, and to explore more systematically how cultural, economic and political differences moderate the cyclical sensitivity of consumers and/or managers. For example, does a stronger presence of discount chains provide a buffer to excessive cyclical swings? Will the growth of a modern retailing infrastructure in many developing countries (Bronnenberg and Ellickson 2015) attenuate or amplify the cyclical fluctuations, and what is the role of a more stringent rule of law system (cf. Steenkamp and Geyskens 2014)?

Apart from more insights on systematic differences between countries, there is also a need to better understand within-country differences. For example, to what extent are firms/brands more affected by regional, as opposed to national (or even global) contractions? And are consumers in rural as opposed to metropolitan regions more or less sensitive to BCs?

\section{Data characteristics: data aggregation and time span}

We further characterize earlier research according to two (inter-related) data characteristics: (1) the total time span covered, and (2) the temporal aggregation level of the data. BC research typically requires consistent time series over multiple decades, which is harder to achieve at a lower level of temporal aggregation (e.g., days or weeks). On top of that, the BC tends to vary more meaningfully over months, quarters or years, rather than over days or weeks.

\section{Time span}

A clear majority of the studies evaluates/contrasts marketing behavior and performance across multiple recession and expansion periods. Since BCs typically last between 1.5 and 8 years (Christiano and Fitzgerald 1998), a time span of several decades ensures that multiple cycles are covered, which allows researchers to move beyond the idiosyncracies of any specific recession and/or subsequent recovery. While some studies covered more than 50 years (e.g., 53 years in some of the categories studied in Deleersnyder et al. 2004), the majority of the studies listed in Tables 1, 2 and 3 covered around 15-25 years of data. Even with several decades of annual data, the number of data points remains limited. To increase the power of the statistical inference, many studies have therefore used meta-analytical techniques across multiple categories (e.g., Deleersnyder et al.
2004; van Heerde et al. 2013) or countries (Deleersnyder et al. 2009; Lamey et al. 2007).

Occasionally, studies have relied on cross-sectional data, and focused on a single recession period. This was the case in Grewal and Tansuhaj (2001), Ou et al. (2014), Srinivasan et al. (2005), and Özturan et al. (2014). Three of these studies use management surveys that were collected right after a severe economic recession that hit Asia in 1997 (Grewal and Tansuhaj 2001), or that hit the U.S. (Srinivasan et al. 2005) and Turkish economy (Özturan et al. 2014) in 2001. Ou et al. (2014) collected consumer survey data in 2010 right after a recession hit the Dutch economy. With surveys, it is hard to systematically collect data for the same entity over multiple time periods. Kumar et al. (2014) and Frösén et al. (2016) nevertheless used a longitudinal survey with multiple waves. Kumar et al. (2014) traced customers' flight purchases and other service information for passengers who completed their surveys at least three times during the data period. These data were subsequently matched with monthly state-level survey data on the general health of the U.S. economy. Frösén et al. (2016), in turn, administered two waves (covering both an economic up- and downturn) of a web-based questionnaire among Finish B2B firms measuring various marketorientation dimensions, which were subsequently linked to objective firm performance.

\section{Temporal aggregation of the data}

Given the multi-decade time span in many studies, it is not surprising that only few studies have relied on data at the quarterly or monthly level. Exceptions are Gordon et al. (2013), who analyzed BCs at the quarterly level, and Hunneman et al. (2015), Ma et al. (2011), and van Heerde et al. (2013) who relied on monthly data. However, these studies cover a shorter time span with 3 years in Hunneman et al. (2015), 5 years (2001-2006) in Gordon et al. (2013), 2 years (2006-2008) in Ma et al. (2011), and 17 years (19932010) in van Heerde et al. (2013), suggesting a trade-off between both temporal characteristics.

\section{Future research}

The monthly BC turning points published by the NBER and other official institutions clearly show that recessions should ideally be tracked at a lower level of aggregation than the yearly level. Moreover, 7 out of the 10 contraction periods identified since 1950 lasted less than one full year. Accordingly, with yearly data, some cyclical fluctuations within a given year may remain unnoticed, and those years that are only partly in a recession period should ideally be treated differently than years where all 12 months are part of the recession. Also, how should statistical accuracy (given that more data points become available when working with multi- 
decade time series) be reconciled with managerial relevance (given that very distant recessions may be less informative/ relevant)? In general, data at a lower aggregation level are preferable. At the same time, the data period should ideally cover multiple full BCs to improve the odds that the results are generalizable, and to avoid that the substantive findings are driven by idiosyncrasies of a single recession or expansion period. Clearly, both objectives may conflict, and further research is needed on the trade-off between them.

\section{Temporary vs. permanent impact of BCs on marketing variables}

Asymmetries in the cyclical patterns suggest that changes in the contraction are not always mirrored by opposite changes in the subsequent expansion. For example, in case of steepness asymmetry, it may take more time for performance to rebound than it took to drop in the contraction. Inspired by this idea, a number of studies have questioned whether all performance changes will eventually be reversed, or whether some of these changes will persist. Lamey et al. (2007), for instance, were the first to show empirically how expansions and contractions affect private-label shares to a different degree, and that the changes in a contraction are not just a temporary glitch. Once consumers switch to private labels to economize on their grocery expenditures, they learn about private-label quality. The increased quality of store brands over the years may positively surprise them, so that some consumers keep buying the cheaper private labels even when bad economic times are long over. Consequently, contractions tend to have a positive impact on private-label growth that is not fully offset in the subsequent expansion. This leaves permanent "scars" on national brands' performance. Lamey (2014) extends these results, and shows that part of the permanent switch to store brands is driven by consumers moving from traditional retailers to hard discounters during contractions. In those stores, consumers are forced to choose from a narrow assortment dominated by store brands.

Asymmetric growth induced by the $\mathrm{BC}$ is also found in consumer expenditures on insurances and gambling in Millet et al. (2012), and in the context of tourism and healthcare spending in, respectively, Dekimpe et al. (2016) and Cleeren et al. (2015). All three studies provide evidence that cyclical adjustments in spending are not just a temporary phenomenon, but also influence the underlying long-term growth pattern in the performance series at hand.

\section{Future research}

Given that only few studies have considered the differential long-run implications of recession-induced cut-backs, numerous research questions remain, such as: How long will such cut-backs in R\&D spending affect the future innovativeness in different categories? Once advertising budgets have been switched to more flexible online media, can more traditional media win the lost contracts back? Once cheaper alternatives (whether budget private labels or cheaper versions of wellknown national brands) have gained acceptance among certain consumer segments, should they keep a similar shelf presence after the crisis, or can (should) this be gradually reduced? And if so, how fast? Also, is the size of the permanent effects related primarily to the length of the preceding recession, or more to its depth?

\section{Existing $B C$ research in marketing: what methods have been used?}

Over the years, research has relied on a variety of methods to make $\mathrm{BC}$ inferences. In reviewing these methods, we distinguish between (1) approaches to assess the general state of the economy (i.e., how is the $\mathrm{BC}$ inferred?) and (2) methods to subsequently link the inferred $\mathrm{BC}$ to the marketing series of interest. An overview is provided in Table 3. In this section, we aim to give the underlying intuition of the different techniques, but refer to the original papers that developed and/or implemented these approaches for a more technical exposition.

\section{Approaches to assess the general state of the economy in a market}

To evaluate the impact of the $\mathrm{BC}$, researchers first need to assess (measure) the general state of the economy. Three different approaches have primarily been used in the marketing literature: (1) official recession dates as published by economic institutions, (2) the direct inclusion of continuous aggregate economic indicators (or survey-based perceptions), and (3) the use of $\mathrm{BC}$ filtering procedures to single out the cyclical fluctuations in these indicators.

\section{Discrete classification by economic institutions}

Various institutions around the world have been involved in identifying official BC turning dates for countries and/or economic regions. They identify months of peaks and troughs in national economic activity to distinguish between contraction and expansion periods: a contraction (recession) is defined as the period between a peak and a subsequent trough, while an expansion is determined as the period between the trough and the next peak.

A prime example is the U.S. National Bureau of Economic Research (NBER) Business Cycle Dating Committee. The NBER maintains a chronology of the U.S. BC since 1854, and its information is publically available at www.nber.org/cycles. $\mathrm{html}$. The NBER does not define a recession in terms of two consecutive quarters of absolute decline in real GDP (a practical definition used by many commentators and analysts; Claessens 


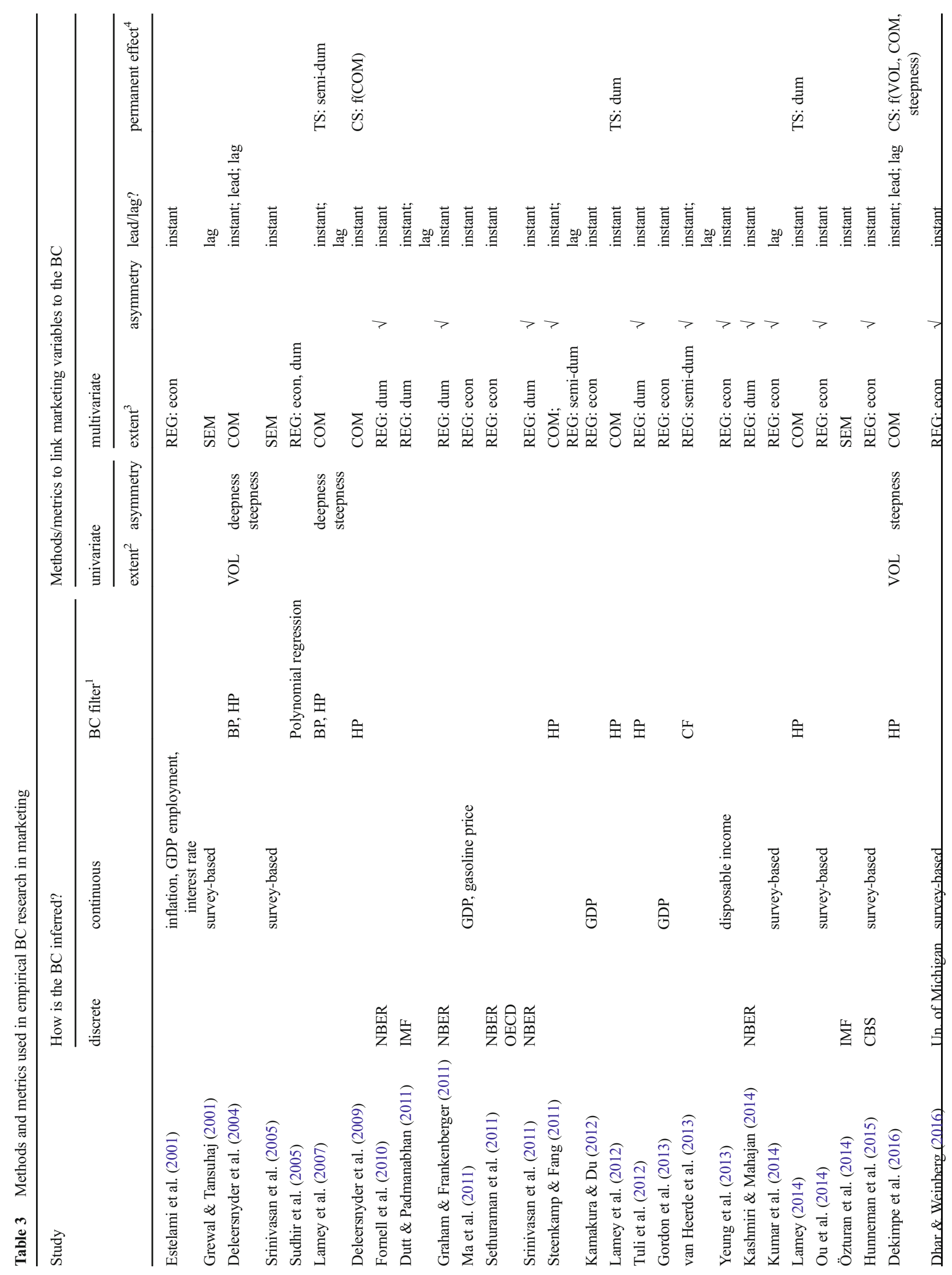




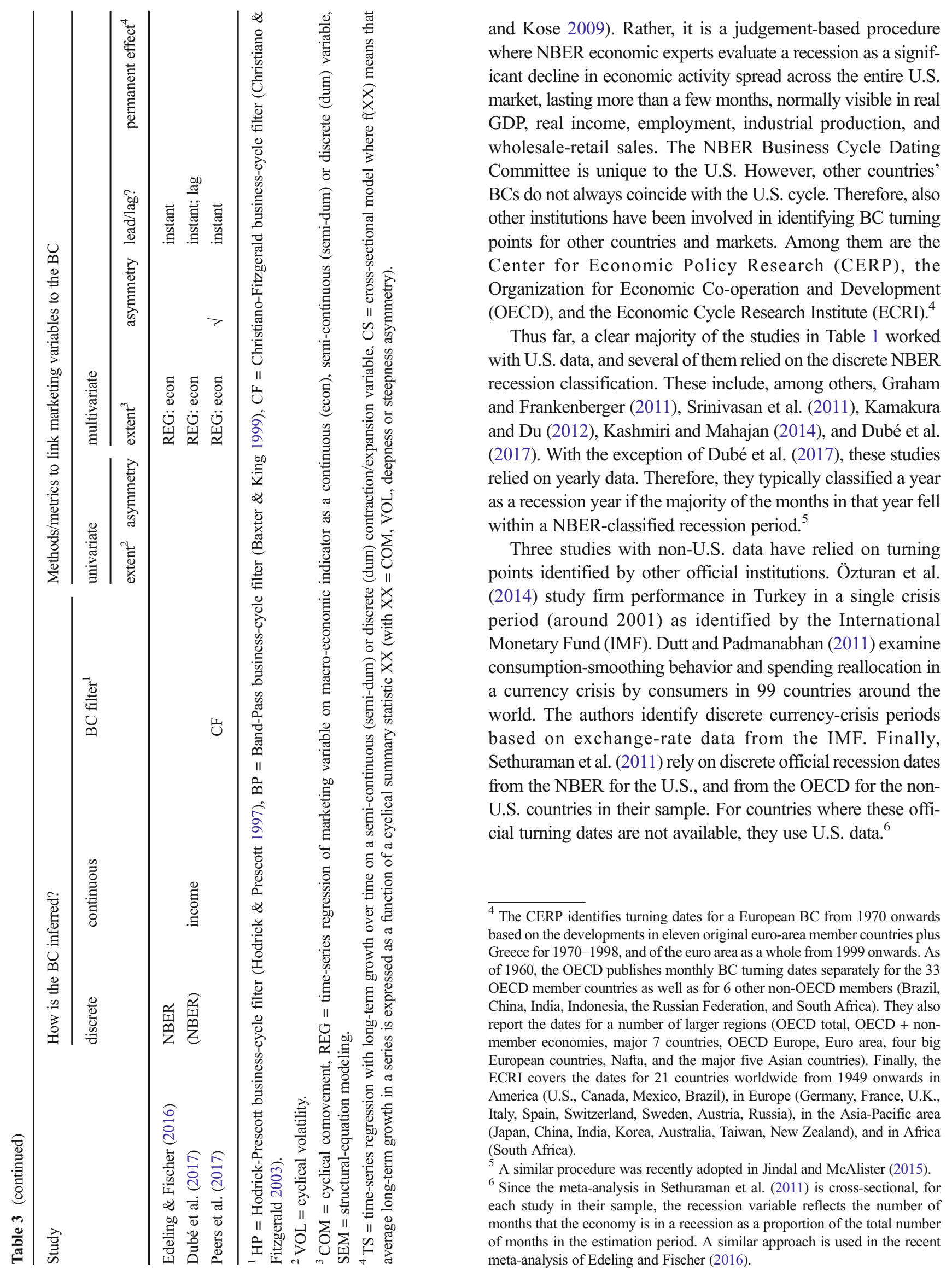


Even though $\mathrm{BC}$ dates as labelled by the aforementioned institutions are well-accepted, and used repeatedly in recent marketing studies, there are some potential drawbacks. First, such dating procedures are often judgment-based approaches, which lack a solid statistical foundation (Stock and Watson 1999). Also, their rigid focus on absolute declines as opposed to growth slowdowns makes them more restrictive, and (importantly) there is little agreement on what economic indicators are most indicative of a recession. Third, not all countries or economic regions have received such an official recession evaluation. To study BCs in countries where there is no official recession chronology, it is hard to justify relying on indicators of other, even nearby or economically similar, countries (Baxter and Kouparitsas 2005). Finally, a discrete classification ignores the strength and uniqueness of individual contraction periods, as well as the speed of decline and recovery. Some contractions are more severe than others, and even within a given contraction period, the earlier versus later parts may affect marketing variables differently. ${ }^{7}$ Accordingly, potentially useful information on the $\mathrm{BC}$ is discarded. The general idea that the $\mathrm{BC}$ is intrinsically a continuous, rather than discrete, concept has long been recognized by various economic researchers (e.g., Baxter and King 1999; or Hodrick and Prescott 1997). These drawbacks have also lead several marketing researchers to favor a continuous approach to infer BCs.

\section{Continuous approximation by official economic indicators}

An obvious extension to a discrete classification of the economic activity into two main phases (expansion vs. contraction, crisis or not) is to infer the state of the economy directly from continuous economic indicators. The market's GDP (or GNP) is by far the most frequently used measure to reflect the general state of the economy. It is often expressed on a percapita basis to take into account changes or differences in population size (see, e.g., Kamakura and Du 2012). Data on GDP (per capita) is publically available, and published by various official (both national and international) institutions, for almost every country worldwide. They are comparable across countries and markets due to international harmonization agreements. GDP represents the total output produced in a country or region during a certain period, and fluctuations in GDP have been found to be at the core of the BC, making it a good proxy for a country's or region's overall economic health (Stock and Watson 1999).

Ma et al. (2011), Kamakura and Du (2012), and Gordon et al. (2013) directly include absolute (levels) or relative

\footnotetext{
$\overline{7}$ Ter Braak et al. (2014), for example, argue that consumers start to exhibit a frugal fatigue near the end of a prolonged contraction period, causing them to occasionally switch back to higher priced national brands and/or explore premium private-label options.
}

(growth rates) GDP values in their analysis to account for the general state of the U.S. economy. ${ }^{8}$ Other studies have relied on (or supplemented GDP data with) other economic indicators, such as household (disposable) income (Dubé et al. 2017; Gordon et al. 2013; Yeung et al. 2013), unemployment (Cha et al. 2015; Estelami et al. 2001), or inflation and interest rates (Estelami et al. 2001). Gordon et al. (2013) show that changes in (regional) household income correlate highly $(\rho=.932)$ with changes in national GDP (Gordon et al. 2013, Fig. 1, p. 6). Ma et al. (2011) focus on the price of gasoline in the U.S. as another relevant macro-economic indicator that significantly influences consumers' weekly shopping behavior over and above the country's GDP. A potential reason to adopt other economic variables than GDP is the need for more disaggregate information, geographically (through more regional or local measures; see, e.g., Kumar et al. 2014), or temporally (when using the daily or weekly variation in gasoline prices; see, e.g., Ma et al. 2011).

While most studies rely on objective or "hard" economic data, occasionally, studies have also used (continuous) survey measures to evaluate consumers' or managers' perception about the severity of the recession affecting them. This was the case in Grewal and Tansuhaj (2001), Srinivasan et al. (2005), and Kumar et al. (2014), among others. The most frequently used perceptual measure is the consumer confidence index (see, for example, Allenby et al., 1996; Dhar and Weinberg 2016; Hunneman et al. 2015; Kumar et al., 1995; Ou et al. 2014; Yeung et al. 2013). When working with the consumer confidence index, one acknowledges that consumers' actual purchase decisions depend not only on their ability to acquire the product, but also on their willingness to do so (Hunneman et al. 2015; Katona 1975). Importantly, people's attitudes and expectations have been found to contribute to cyclical fluctuations in excess of the impact of the actual changes in their income level (Carroll et al., 1994).

Continuous macro-economic aggregates or survey-based measures are not necessarily the best proxy for the cyclical state of the economy. Not all fluctuations in GDP, for instance, are driven by BCs. The long-term upward trend underlying real U.S. GDP since 1950, for example, shows an average yearly growth of $3.2 \%$ (source: www.bea.gov/national), which masks the cyclical ups and downs of interest. Also, unemployment series or inflation rates have been found to show clear seasonal patterns that should not be confused with BCs. Economists (see e.g., Baxter 1994) showed in this context that when a researcher is specifically interested in BC ups and downs, one should remove the (often upward) longterm trend, as well as the short-term high-frequency variation, from the series, and only retain the fluctuations at $\mathrm{BC}$

\footnotetext{
${ }^{8}$ In a somewhat different operationalization, Tavassoli et al. (2014) measure the intensity of the recessionary environment with the number of negative GDP growth quarters in the previous year.
} 
periodicities. To do this, BC filters have been developed, which have become popular in marketing as well.

\section{Inferred from official economic indicators through BC filters}

The economics literature has developed various filtering techniques to extract $\mathrm{BC}$ information from aggregate economic series. An overview of alternative filtering techniques is provided in Canova (1998) and Baxter and King (1999), among others. BC filters are designed to separate fluctuations related to the $\mathrm{BC}$ from other sources of variation in the series of interest, such as short-term (irregular or periodic) fluctuations and/or a long-term trend. Based on the observation from several NBER researchers (see, e.g., Burns and Mitchell 1946; Christiano and Fitzgerald 1998) that BCs typically last between 1.5 and 8 years, the underlying idea of BC filters is to pass through all components of the time series with periodic fluctuations between, say, 6 and 32 quarters. These filters are easy to implement and, with proper adaptation, can be used on data series with different levels of temporal aggregation. Interestingly, even though the filters have been designed and applied in the economics literature to detect BCs in various aggregate economic series (see, e.g., Stock and Watson 1999), these techniques can also be applied directly to the marketing performance or conduct series of interest in order to extract the variation that occurs at (and is potentially related to) $\mathrm{BC}$ periodicities, as we explain below.

Thus far, three different BC filters have become popular in the marketing literature (see column 4 of Table 3): the Hodrick-Prescott (HP) low-pass filter (Hodrick and Prescott 1997), the Baxter and King band-pass (BP) filter (Baxter and King 1999), and the Christiano and Fitzgerald (CF) random walk band-pass filter (Christiano and Fitzgerald 2003). ${ }^{9}$ The main distinction between a low-pass and a band-pass filter is based on the type of information that is retained after filtering. A low-pass filter passes through all the low-frequency variation that occurs at a periodicity of longer than 8 years, corresponding to the long-term fluctuations in the series that exceed the (typical) maximum length of a BC. The latter is subsequently obtained by subtracting the filtered series from the original series. The band-pass filter, in turn, directly passes through all fluctuations within a certain frequency band (typically set between 1.5 and 8 years for BCs). As such, the outcome of the filter is already the $\mathrm{BC}$ component in the series at hand. Both the Baxter and King (1999) and the Christiano and Fitzgerald (2003) filter are built on this band-pass principle. However, contrary to the original BP filter of Baxter and King (1999) that relies on symmetric filter weights for several

\footnotetext{
${ }^{9}$ A somewhat different but related approach is applied in Sudhir et al. (2005), who use a (fifth-order) polynomial trend regression on the consumerconfidence index to separate upward-sloping from downward-sloping demand periods.
}

leads and lags that curtail/trim the filtered series with six years of data (three years at the beginning and three years at the end of the sample), the CF filter is explicitly designed to use the entire time series. As such, no observations are lost in the filtered series. We refer to the original papers for the technical details on the respective derivations.

Several studies have used the HP filter to extract the cyclical fluctuations in both (per capita) GDP and various marketing series, including sales (Deleersnyder et al. 2004), privatelabel share (Lamey et al. 2007, 2012), discounter share (Lamey 2014), and marketing conduct series as advertising, innovations, promotions, and/or regular prices (Deleersnyder et al. 2009; Lamey et al. 2012). Deleersnyder et al. (2004) and Lamey et al. (2007) implement both the HP and BP filter. They find a good correspondence between the $\mathrm{BC}$ fluctuations extracted with both filters, and all main results were replicated.

A key consideration in the choice of filter is the temporal aggregation of the data. With yearly data, both the HP and BP filter produce similar results. When data is available at a lower level of aggregation, the HP filter will also retain seasonal and other short-term high-frequency noise that is not associated with the BC. Given that this is removed by the BP filter, the latter is preferred for studies where data is available at the quarterly, monthly or lower levels of temporal aggregation. Thus far, only van Heerde et al. (2013) have implemented BC filters on monthly data. In this study, the authors opted for the $\mathrm{CF}$ random walk filter over the more general BP filter to avoid losing observations at the beginning and end of the series.

\section{Alternative approaches to assess the BC: a comparison}

Any empirical examination of the $\mathrm{BC}$ involves an identification of the general state of the economy. The three approaches discussed before extract somewhat different, yet related, information. In Fig. 2, we illustrate their relationship using yearly U.S. real GDP data (1950-2015).

When researchers infer the state of the economy directly from a continuous economic indicator such as U.S. national GDP (cf. "continuous approximation by official economic indicators"), the original series (presented in Panel A) is included directly into the analysis. Interestingly, the majority of the over-time variation in aggregate GDP is related to the long-term upward trend in the series, which masks to some extent the cyclical variation around it. Comparing these fluctuations with the discrete official economic contraction periods identified by the NBER and represented in Panel A and B with the grey bars (cf. "discrete classification by economic institutions"), we observe a growth slowdown, and sometimes even an absolute decline, in national GDP in the time periods where an official recession period is identified. Interestingly, as shown in Panel B, these BC swings get amplified after implementing a $\mathrm{BC}$ filter on the original aggregate GDP series (cf. "Inferred from official economic indicators 


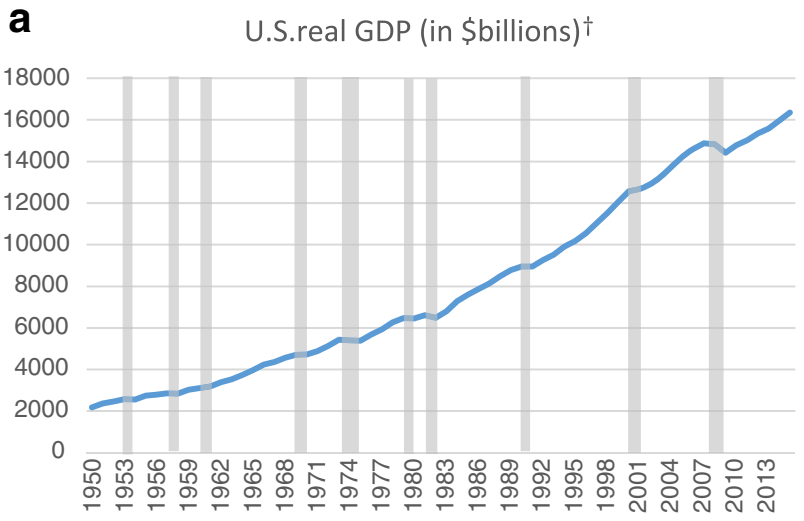

b

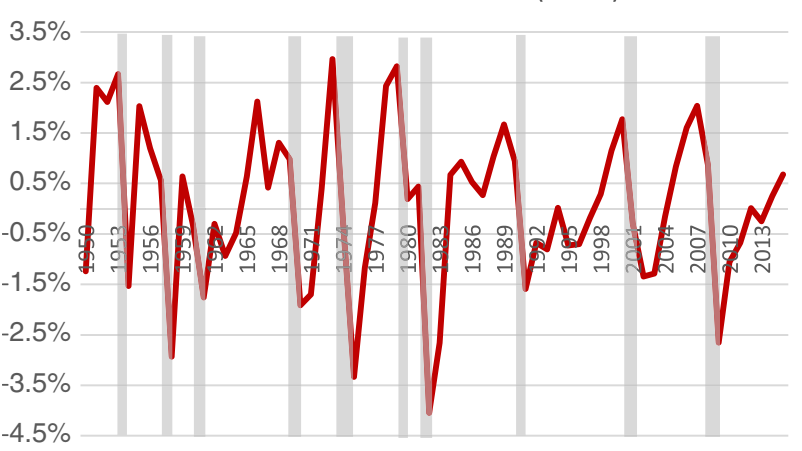

† Grey shaded columns represent the official NBER contraction periods *Data source: http://www.bea.gov/national/

Fig. 2 Relationship between alternative approaches to assess the BC, applied to yearly U.S. real GDP (1950-2015)*

through BC filters"), while the dominant long-term growth pattern has been removed. In combination, while all three approaches are largely in agreement as to when the contractions/expansions occur, they provide intrinsically different information on the extent of the $\mathrm{BC}$ swings.

\section{Methods and metrics to describe $\mathrm{BC}$ patterns in marketing}

Once the general state of the economy has been identified, researchers still need to describe and summarize different $\mathrm{BC}$ properties in the marketing series of interest. As pointed out in Table 3, both univariate and multivariate methods have been adopted to do so. Univariate techniques focus on understanding the extent of (or asymmetries in) the cyclical ups and downs within a given marketing or performance series, but do not consider whether these fluctuations are synchronized (coincide with) those in the aggregate economy. As such, these methods are used when prior BC filters have been applied to the respective series. Multivariate approaches, in turn, explicitly relate fluctuations in the focal variables to cyclical fluctuations in the aggregate economy. In this case, all three approaches to infer the $\mathrm{BC}$ in the economy at large can be used.
Marketing researchers have mainly evaluated the following four BC properties: (1) the extent of the BC swings, (2) asymmetries across cyclical ups and downs, (3) the exploration of leading/lagging effects of BC fluctuations, and (4) the potential permanent impact of $\mathrm{BCs}$ on marketing series.

\section{Methods to examine the extent of $B C$ fluctuations}

Cyclical volatility Deleersnyder et al. (2004) and Dekimpe et al. (2016) both use the univariate cyclical volatility (VOL in Table 3) to describe how large the cyclical swings are in, respectively, yearly durable sales and the number of incoming international tourists. This measure is acquired by first applying a $\mathrm{BC}$ filter to the log-transformed marketing series to extract those fluctuations that occur at $\mathrm{BC}$ periodicities. After this filtering, the standard deviation of the resulting cyclical series expresses, in percentage terms, the extent of cyclical variability in the series at hand. For instance, the average cyclical variability in postwar U.S. GDP has been found to be about 2\% (Stock and Watson 1999). This volatility measure can be expressed relative to the normal level or growth rate in the series, but also a comparison across series is possible. Stock and Watson (1999), for example, compare the cyclical volatility across numerous macro-economic series, while Deleersnyder et al. (2004) compare the cyclical volatility across 24 durables. Importantly, both studies also relate the cyclical volatility in the relevant economic or marketing series to the cyclical volatility in national GDP over the same period to see whether the former are affected more or less than the economy as a whole.

Cyclical comovement A multivariate extension of the cyclical volatility statistic is the cyclical comovement elasticity (COM in Table 3). This alternative measure also starts with a BC filter implemented on the (log-transformed) series. After filtering both the marketing series and a general economic (mostly GDP-based) metric, a regression of the former on the latter results in a cyclical comovement elasticity (we refer to Lamey et al. 2007 for a formal derivation). It expresses how a $1 \%$ change in the $\mathrm{BC}$ translates into an $\mathrm{X} \%$ change in the cyclical marketing series of interest. While its absolute value reflects the extent of cyclical fluctuations in the series, the sign and significance of the estimate are informative on the direction of the impact: pro-cyclical, when changes occur in the same direction as the economy $(\mathrm{COM}>0)$; countercyclical when changes are in the opposite direction $(\mathrm{COM}<0)$; or $a$-cyclical when the cyclical fluctuations are unrelated to those in the overall economic activity $(\mathrm{COM}=0)$. Also, because of its unit-free nature, comparisons across marketing instruments, categories or countries are straightforward.

Most research in marketing that quantifies the cyclical comovement elasticity shows that the $\mathrm{BC}$ fluctuations in performance (Deleersnyder et al. 2004; Cleeren et al. 2015; Dekimpe et al. 2016) and marketing conduct (Deleersnyder 
et al. 2009; Lamey et al. 2012) are pro-cyclical, and often amplified, as evidenced by a positive cyclical comovement elasticity that exceeds one. Deleersnyder et al. (2009), for instance, report an average comovement elastivity of 1.4 for advertising spending, implying that every percentage deviation from GDP's long-term growth translates into a corresponding deviation of $1.4 \%$ in advertising spending. Similarly, the average co-movement elasticity for the number of visitors travelling to New Zealand from 30 countries reported in Dekimpe et al. (2016) was 1.27, which is higher than most other economic sectors contained in GDP, but still smaller compared to spending on consumer durables (which has a comovement elasticity of around 2; Deleersnyder et al. 2004). However, Lamey et al. $(2007,2012)$ report a counter-cyclical comovement elasticity in private-label performance of around -1 , while Lamey (2014) shows evidence of a counter-cyclical comovement elasticity in discounter share of -2.37 . Hence, $\mathrm{BC}$ downturns enhance both private-label and discounter success.

\section{Time-series regression on a continuous economic variable}

Several studies have performed a regression over time of a marketing (conduct or performance) variable on a continuous economic-activity series (REG: econ in Table 3). Similar to studies using filtering approaches, national GDP (per capita) is the dominant measure to capture the general state of the economy when a continuous BC measure is used (Estelami et al. 2001; Kamakura and Du 2012; Gordon et al. 2013). But also other metrics like inflation, unemployment and interest rates (Estelami et al. 2001), household income (Dubé et al. 2017; Yeung et al. 2013), gasoline prices (Ma et al. 2011), or the regional U.S. Gallup-Healthways perceived economic wellbeing index (Kumar et al. 2014) have been used to proxy for the economic state in these regressions.

Time-series regression on a (semi-)dummy economic variable Other studies have relied on a time-series regression of the marketing series on a recession dummy to capture the discrete state of the economy (REG: dum in Table 3). For studies on U.S. data such as Graham and Frankenberger (2011), Srinivasan et al. (2011), and Kashmiri and Mahajan (2014), the NBER recession periods were the basis for the recession dummy. Also Dutt and Padmanabhan (2011) use a dummy-regression approach, but they examine data for 99 countries worldwide, many of which do not publish any official recession dates. Given that they study the impact of a currency crisis (rather than an economic crisis), their classification is based on the occurrence of a currency depreciation in the country's exchange rates as published by the IMF.

Finally, several studies (see, among others, Steenkamp and Fang 2011 and van Heerde et al. 2013) have constructed a semidummy variable, which they subsequently use in a (time-series) regression to capture the impact of the BC (REG: semi-dum in Table 3). In a first step, BC filters are applied to aggregate GDP.
The semi-dummy for the contraction takes the value of 0 when cyclical GDP increases, while it represents the magnitude of the contraction when cyclical GDP decreases. Specifically, one computes the drop relative to the previous peak in the cyclical GDP series. Similarly, another semi-dummy can be created to capture the magnitude of expansion periods (with the size in each period computed relative to the previous trough in the cyclical GDP series). We refer to Lamey et al. (2007) for an in-depth discussion on this operationalization.

Cross-sectional methods A number of studies (see, e.g., Grewal and Tansuhaj 2001; Srinivasan et al. 2005; and Özturan et al. 2014) have used a cross-sectional approach (like structural-equation modeling or SEM in Table 3) to study differences in firms' marketing conduct and performance depending on the perceived state of the economy. These studies collected survey data from managers on firm performance and various marketing-strategy aspects, while also collecting information on the managers' perceived market uncertainty or perceived recession severity.

\section{Methods to capture BC asymmetries}

Various studies have tested for asymmetries over the BC. Here too, univariate and multivariate methods have been used (see Table 3). Univariate asymmetry statistics capture BC asymmetries within a series, and evaluate how cyclical movements in the series during a contraction deviate from the cyclical movements in the subsequent expansion period. Multivariate asymmetries, in turn, are able to detect differences in the strength and/or direction of a marketing relationship (between series) across expansion and contraction phases.

Univariate asymmetries To describe asymmetries within a time series, Sichel (1993) distinguishes between asymmetry in the rate of change within a series (=steepness) and asymmetry in the level (=deepness) of the peaks and troughs across alternative $\mathrm{BC}$ phases. Both types are inferred from the $\mathrm{BC}$ filtered series through the third-order moment (i.e., the skewness statistic). Since deepness asymmetry relates to deviations in the absolute level of the series, it is derived directly from the BC filtered series. Steepness asymmetry, in turn, relates to the slope or growth rate in the cyclical series, and hence, can be determined by computing the skewness statistic on the first difference of the cyclical component in the series of interest (Sichel 1993). Due to the low power of the individual skewness tests, especially when working with annual data, some marketing researchers have relied on the more powerful non-parametric "Triples" test (we refer to Randles et al., 1980, or Verbrugge 1997 for a technical discussion). Alternatively, multiple individual tests have been combined meta-analytically to further increase the power of the inference (e.g., Lamey et al. 2007, 2012; Deleersnyder et al. 2004, 2009; Dekimpe et al. 2016). 
Univariate deepness and steepness statistics have been derived in Deleersnyder et al. (2004), and Lamey et al. (2007), while Dekimpe et al. (2016) consider only steepness asymmetry. Deleersnyder et al. (2004) find both types of asymmetries in the cyclical volume sales of consumer durables. Even though contractions are shorter than most expansions, they elicit swift downwards adjustments in durable purchases among households, while the upward adjustments take considerably more time. Also, the depth of the recessionary troughs is deeper (further below the mean level) than the peaks in the subsequent expansion are high. Interestingly, Lamey et al. (2007) find an opposite pattern in private-label success, in that they benefit more during contractions than they suffer in expansions. Here, consumers switch faster (steepness) and further (deepness) towards private labels during contractions than they switch back to the original national brands in the subsequent expansion period. In the international tourism industry, Dekimpe et al. (2016) could not observe the expected steepness asymmetry in the number of visitors to New Zealand.

Multivariate asymmetries Several studies also evaluate asymmetries in the relationship between variables over the BC. Here, interaction terms in multivariate regression methods are used to evaluate if the strength and/or direction of the relationship between a marketing and performance variable differs across contractions versus expansions.

Interestingly, all three approaches discussed in the "Approaches to assess the general state of the economy in a market" section to proxy the $\mathrm{BC}$ have been used in the interaction terms. Fornell et al. (2010), Graham and Frankenberger (2011), Srinivasan et al. (2011) and Kashmiri and Mahajan (2014) all use a binary contraction dummy in the interaction, with the contraction years identified according to the official NBER recession dates. Steenkamp and Fang (2011) and van Heerde et al. (2013), on the other hand, rely on prior BC filters to self-extract the cyclical fluctuation in national GDP, which enter the interaction through the contraction semidummy discussed above. Tuli et al. (2012) use a similar identification procedure to determine the contraction period (rather than the NBER dates), but include a dummy (rather than semi-dummy) variable in the interaction term. Finally, Kumar et al. (2014), Hunneman et al. (2015), and Dhar and Weinberg (2016) add an interaction effect between the focal marketing-conduct variable and a continuous economic proxy. Kumar et al. (2014) rely on the perceived economic well-being index published by the Gallup-Healthways website for different U.S. regions, Hunneman et al. (2015) on the Dutch Consumer Confidence index as published by the Central Bureau of Statistics (CBS), while Dhar and Weinberg (2016) use the monthly U.S. consumer-sentiment index published by the University of Michigan.
Methods to explore lead or lagging effects

The majority of the studies presented in Table 3 only considered instantaneous effects of the BC. Still, literature in economics has revealed that certain variables may have a lead (labor vacancies) or lagging (unemployment) relationship with the general state of the economy, or that the impact is not fully captured in the same period, but rather extends beyond the current period (Mascarenhas and Aaker 1989; Stock and Watson 1999).

Thus far, few marketing studies have examined such lead/ lagging effects. Deleersnyder et al. (2004) extend the static comovement estimation described before, and include oneyear lead and lagged variables of the cyclical GDP component to allow for potential dynamic effects. However, the resulting dynamic comovement elasticity was very similar to the static one. This was also the case in Dekimpe et al. (2016). Also Dutt and Padmanabhan (2011) and Steenkamp and Fang (2011) evaluate a delayed impact by adding a three-year and a one-year lag to their models, respectively. While Steenkamp and Fang (2011) find little empirical support for the presence of any dynamics, Dutt and Padmanabhan (2011) find for some of the countries in their sample significant effects of the currency crisis for up to three years. Lamey et al. (2012) test for potential lags for the expansion and contraction separately in their growth model, but concluded on the basis of information criteria that no such dynamics were required. A somewhat different method is used in van Heerde et al. (2013). They used an error-correction model, which allows to directly infer short- and long-run elasticities, which were both interacted with the aforementioned semi-dummies to assess how they were moderated by the size of, respectively, expansion and contraction periods.

Interestingly, in the cross-sectional analyses by Grewal and Tansuhaj (2001), and Özturan et al. (2014) the authors linked marketing activities during the contraction to performance data right after it. Also Kumar et al. (2014) rely on surveys, and link consumer travel activity to the state of the economy in the month preceding the actual travel consumption.

\section{Methods to examine the permanent impact of $B C S$}

Most methods described so far were able to capture the temporary impact of the $\mathrm{BC}$, where any adverse (or beneficial) effect during the contraction will eventually be restored in the subsequent expansion, even though this could take somewhat more time (in case of univariate cyclical asymmetries). A number of marketing studies, however, further evaluate whether temporary BC fluctuations can have a permanent impact by altering the underlying long-term growth rate and/or level of the series of interest. These studies rely either on timeseries growth models, or on cross-sectional models that link 
average growth rates to $\mathrm{BC}$ properties across a large set of marketing series.

Time-series based methods To examine whether cyclical shocks have a permanent impact on a series, BCs can be related to the series' underlying growth. For example, the first difference of the series (capturing the change/growth in the series) can be regressed on current (and lagged values) of a contraction and/or expansion (semi-)dummy to evaluate if the growth in the series is affected differently by various stages of the BC. ${ }^{10}$ By working in the first differences of the series (the adequacy of which can be assessed through unit-root testing; see, for example, Dekimpe and Hanssens 1995), one allows for the possibility of persistent effects. By splitting the BC in two phases, the persistent effect of a contraction is not necessarily cancelled out in the subsequent expansion. Such an asymmetric growth model was used in Lamey et al. (2007) to examine differential growth rates in private-label share, and in Millet et al. (2012) in their study on consumer spending on gambling and insurances over the $\mathrm{BC}$.

Both Lamey et al. (2007) and Millet et al. (2012) quantify the severity of an expansion (contraction) in the form of a semi-dummy that captures how much the $\mathrm{BC}$ has increased (decreased) relative to its previous trough (peak), and 0 in the opposite economic phase. Lamey et al. (2012) and Lamey (2014) simplify this growth model and regress the first differenced series on an intercept and a binary recession dummy. With this model, the intercept captures the series' longterm underlying growth pattern in an expansion, whereas the coefficient associated with the recession dummy quantifies the incremental long-term growth during a contraction year that is not cancelled out in future expansion periods.

Cross-sectional methods Alternatively, marketing studies have also examined the permanent effects of BCs based on cross-sectional analyses. Here, one first derives on a broad sample of time series the cyclical properties within each series (such as the cyclical comovement elasticity or the univariate asymmetry statistics), as well as the average long-term growth rate in that series. In a second step, these cyclical properties are linked in a cross-sectional regression to the corresponding average long-term growth rate in the respective series, while controlling for other factors potentially affecting the series' growth.

This approach was first implemented by Deleersnyder et al. (2009) to evaluate (across countries/firms) the impact of cyclical advertising adjustments (reflected in the comovement elasticity) on the long-term growth in the advertising industry, on the growth in private-label performance, and on the long-

\footnotetext{
${ }^{10}$ While some studies have worked with the first differences of the original series (see, for example, Lamey et al. 2007; Millet et al. 2012), others have worked with the first differences of the long-run trend series (i.e., the series from which the BC fluctuations have been filtered out; see, e.g., Lamey et al. 2012; Lamey 2014).
}

term growth in firms' stock prices. More recently, Cleeren et al. (2015) and Dekimpe et al. (2016) implemented this approach to evaluate the long-term consequences of cyclical reductions in healthcare spending and international tourism, respectively. Cleeren et al. (2015), for instance, linked the comovement elasticities of healthcare expenditures to the long-term average growth in different countries' mortality rate.

\section{Future research}

Most of the methods to extract $\mathrm{BC}$ information from marketing series have been developed in the economics literature, which also contains numerous (often simulation) studies on the respective pros and cons of alternative approaches. ${ }^{11}$ On the positive side, this means that the various methods have been extensively validated. Still, marketing studies rarely motivate their choice for a specific approach, giving this choice somewhat of an ad-hoc feeling. For example, Lamey et al. (2007) and (2012) both applied a BC filter. The former subsequently derived semi-dummy variables to quantify the extent (size) of the contraction and expansion, while a binary dummy variable was used in the latter. Similarly, studies working with the NBER recession dates either use the proportion of months in a given year in the recession period (cf. Edeling and Fischer 2016), or a binary classification based on whether the majority of months falls in a recession period (e.g., Srinivasan et al. 2011), and some studies formally test for a dynamic comovement elasticity, while others immediately opt to focus on the instantaneous version. We advise authors (1) to better motivate their specific classification/procedure, and (2) to more extensively assess the robustness of their substantive insights to the specific approach that was adopted.

With respect to the diverse set of metric and methods to describe $\mathrm{BC}$ patterns in the data, we conclude from our review that (1) depending on the type of phenomenon one is interested in, different approaches may be required, and (2) different patterns can co-exist in the same series (e.g., asymmetries can be present with or without any long-term impact or change in the underlying trend). Substantively, more research is required to evaluate possible relationships between these phenomena. On the methodological side, new approaches that combine these analyses or that allow to study more complex cyclical patterns (e.g., accounting for dynamics in $\mathrm{BC}$ asymmetries) can further advance our understanding in this field. Finally, survey research could be an important instrument to reveal the underlying mechanisms for the observed $\mathrm{BC}$ patterns in consumer and managerial behavior.

\footnotetext{
${ }^{11}$ See, among others, Baxter and King (1999), Burnside (1998), or Canova (1998).
} 


\section{Key insights and areas for future research}

BCs have gained increasing attention from marketing scholars over the past 15 years, and the number of articles published on the topic has grown substantially. Various studies have looked at a variety of $\mathrm{BC}$ phenomena, and a broad set of research techniques has emerged to study the impact of BCs on performance, marketing decisions, and marketing effectiveness. This paper reviewed and synthesized the current state of knowledge on the topic.

Several managerial takeaways emerged from this growing body of research.

- The impact of BCs can manifest itself in many ways. Retailers as well as manufacturers should be aware that consumers, who are shaken out their habitual buying behavior and who are pushed towards alternative (often more deliberate) purchase decisions to economize on their spending during contractions, can adopt a wide variety of coping strategies. They not only opt to cut back on the quantity of products and services they buy, they may also shift budgets across categories, or switch to cheaper brand alternatives (and stores) within the category, while purchases may also be postponed till better times. Importantly, one should not count on the fact that customers will quickly or fully revert these decisions in the subsequent expansion. Having enough flexibility in one's assortment or banner composition may help prevent that consumers switch to competing brands or retailers when the $\mathrm{BC}$ enters a new stage.

- Don't just stand at the sideline. Even though the occurrence and depth of a recession is beyond their individual control, managers can be held accountable in part for the impact a recession has on their brands' performance. Firms have been found to change their strategies and activities significantly over the BC. Almost all major marketing instruments tend to be adjusted when the economy winds down. Importantly, these marketing adjustments drive to some extent consumers' purchase adjustments in response to adverse economic times. Thus, economic downturns can offer opportunities to firms that make the most appropriate adjustments.

- Don't automatically follow the blind. Blindly following the herd in an attempt to adhere to the wisdom of the crowd is not necessarily optimal. It has been shown repeatedly that firms which go against the tide can benefit from worsening economic conditions, both during and following the recession. If everyone cuts back, simply maintaining their spending or cutting back less can already help a brand or firm to outspend and outperform their competitors.

- Keep a holistic view. Automatically going against the grain is not always optimal either. The optimal strategy should take into account multiple factors: the cyclicality of one's demand to the $\mathrm{BC}$, the cyclicality of marketing effectiveness and the cyclicality of the profit contribution. If all three evolve pro-(counter-)cyclically, spending should be pro-(counter-)cyclical too. Occasionally, however, their evolution differs, and the elasticity magnitudes need to be compared. The directionality (pro- or counter-cyclical) of the net elasticity determines which policy is recommended. Thus, a single-minded focus on only one of these dimensions may well result in suboptimal decisions.

- No size fits all. The dependence of brands and firms on the $\mathrm{BC}$ is not uniform across industries nor countries. The way in which consumers adjust their spending behavior depends not only on the product category (e.g., groceries vs. durables), but also on their quality tier. Also, characteristics related to the necessary or pressing nature of the product, its ability to be stocked, and the substitutability among the brands' alternatives should be taken into account. Finally, industry and spatial differences in the BC impact open opportunities to smooth out some of the economic fluctuations through diversifying activities across products and/or markets.

- Be prepared. History has made clear that after years of economic prosperity, the economic tide will turn again. To weather these harsh economic times, which will come around sooner or later, managers should not just spend more on marketing in the recession, they also need to spend existing budgets more smartly by shifting some of the marketing expenses over time and over products. Therefore, spending strategies during prosperous economic times may need some smoothing and some of these budgets could be put aside to weather the next recession period, and thereby prevent that some of the customers may be irrevocably lost.

Not surprisingly, numerous research opportunities remain in this area that has only recently received due attention in the academic marketing literature. Several specific opportunities have already been indicated throughout the text. In the following sections, we summarize three general domains in need of more research: (1) a broadening of the research scope, (2) an exploration of relevant contingency factors, and (3) a deepening of the normative recommendations.

\section{Broadening the research scope}

Even tough an initial set of empirical generalizations on the impact of economic cycles has emerged (see, for example, Hanssens 2015, pp. 19-27, or Tellis and Tellis 2009), it would be useful to expand the scope of enquiry along a number of dimensions.

First, as in many other domains of marketing research, the majority of studies thus far has focused on mature (U.S. and/or Western European) economies. It would be useful to expand 
the geographic scope of the studies to include more developing economies, and to explore, for example, in more detail how cultural, economic and political differences moderate the cyclical sensitivity of consumers and/or managers. In terms of the marketing-mix instruments studied, it would be good to consider a more diverse set of (more disaggregate) marketing instruments. In addition, it would be good to also consider other (non-grocery, non-travel) sectors, and to explore in detail the heterogeneity within a given sector.

Second, even though the number of studies has increased considerably over the last two decades, the number of distinct research questions has not increased at the same rate. Indeed, several studies had a very similar substantive focus. For example, the shift in grocery shopping towards private labels in economically more difficult times has been documented in, among others, Deleersnyder et al. (2009), Lamey (2014), Lamey et al. (2007, 2012), Ma et al. (2011), and Dubé et al. (2017). Within the service industry, (international) tourism has been subjected to an elaborate BC analysis in Kumar et al. (2014), Dekimpe et al. (2016), and Peers et al. (2017), and the impact of changing gasoline prices on grocery shopping has been studied in Ma et al. (2011) and Gicheva et al. (2010), among others. Given the different research methods adopted in some of these studies, this either increases one's confidence in the findings in case comparable conclusions are reached (as then the power of diverse methods is harnessed; Hamilton 2016), or can stir an interesting debate if not. ${ }^{12}$ Given the growing body of research on various BC phenomena implementing a plethora of different techniques, a formal meta-analysis could be helpful to identify the relative contribution of various drivers. Still, it is essential to expand the set of research questions, and several useful avenues have been discussed throughout the text at the end of the respective sections.

In addition, a number of well-established research paradigms will need to be adapted to better reflect the financial constraints that consumers and firms face during economic crises. Bradlow (2009), for instance, wonders whether currently used choice models adequately reflect the decision rules that consumers use during economically harsh times. For example, do current specifications adequately capture that some consumers become more (price) lexicographic in their decision process? Do they allow that the weight attached to both price (Gordon et al. 2013) and non-price (Hunneman et al. 2015; Mukherjee and Bonfrer 2015) attributes can vary systematically and predictably with the state of the economy? And do stringent budget constraints and the no-choice option receive sufficient attention?

\footnotetext{
12 Dubé et al. (2017), for example, use a different identification strategy than Lamey et al. (2007, 2012), and come to much smaller effect sizes for the impact of a recession on private-label growth.
}

In a similar vein, one may wonder what elements of customer-lifetime-value models (e.g., retention rates, discount rates) should be allowed to vary with the state of the economy (Bradlow 2009), whether social contagion (also through online media) is more/less influential in contraction periods, whether certain business models (like Groupon's) become more effective during recessions than during vibrant economic times (Reibstein 2011), in what stage of the BC relationshipmarketing and customer-loyalty programs have the best return on investment (Beck et al., 2015; Ou et al. 2014), whether consumer learning is affected, and whether well-accepted marketing-strategy frameworks still hold under extreme economic conditions (Day and Moorman 2010; Quelch and Jocz 2009). Finally, more research is needed how to optimally organize the marketing organization (e.g., in terms of capabilities) to reduce BC induced volatilities (Moorman and Day 2016).

\section{Development of relevant contingency frameworks}

Initially, empirical insights were mostly presented as main effects. For example, customers become more price sensitive and switch to private labels in economic downturns, while managers tend to reduce advertising and $R \& D$ support in recessionary times. However, as the field developed, more and more moderating effects have been added to the discussion. For example, the moderating role of market orientation has been documented in both Özturan et al. (2014) and Frösén et al. (2016), Kashmiri and Mahajan (2014) explore the link with family ownership of the firm, and van Heerde et al. (2013) show how the price and advertising elasticity is affected differently for, respectively, premium-mass, value-mass, premium-niche and value-niche brands.

It is of paramount importance to identify additional moderating factors, as these set the limits of generalizability (Whetten 1989), and constitute crucial boundary conditions for existing BC theory in marketing (MacInnis 2011). Numerous research opportunities exist in this respect. For example, what is the role of, respectively, the length and the depth of the crisis in explaining customer and managerial adjustments? ${ }^{13}$ Are all brands equally affected when consumers lose trust in the economic system, or are leading brands (given that they may be seen to benefit most from this unfair system) affected disproportionately (Beck et al., 2016). Also, how important are regional (within-country) differences in economic health? Are consumers in rural, as opposed to metropolitan, regions more or less sensitive to BCs? Do consumers favor local over global brands more during contractions than during

\footnotetext{
${ }^{13}$ Talay et al. (2012), for example, show how the severity of the recession presents a boundary condition to the benefits of launching new products during economic downturns, ter Braak et al. (2014) discuss the role of the length of the economic cycle, while Mascarenhas and Aaker (1989) distinguish between early and late contraction phases.
} 
expansions? And what characteristics drive consumers' choice of coping strategy?

\section{Development of more actionable normative guidelines}

Most research findings have been descriptive in nature, i.e., how consumers and managers typically adjust their behavior when economic conditions change. Even though some studies have offered normative recommendations on how firms/brands should (directionally) change their behavior, these recommendations are often based on different metrics, and sometimes contradictory. For example, Deleersnyder et al. (2009, p. 634, italics added) argue that "if the company has the financial resources, it should implement an advertising strategy that is inelastic - or even anticyclical - with respect to the business cycle." This recommendation was echoed in Lamey et al. (2012), who conclude, "when the economy winds down, manufacturers should try to maintain their current spending or even raise advertising if that is financially feasible" (p. 15, italics added). Van Heerde et al. (2013), in contrast, arrive at a completely opposite recommendation, as they recommend pro-cyclical spending. However, while the first two studies base their conclusion on the cyclicality of demand, van Heerde et al. (2013) use the cyclicality in advertising's (sales) elasticity to arrive at their recommendation. Steenkamp and Fang (2011) use the cyclicality in advertising's (market-share) elasticity, yet join the counter-cyclical ranks. In an attempt to solve this conundrum, Peers et al. (2017) argue that the recommendation for pro- versus counter-cyclical spending should consider a tradeoff between three metrics: the cyclicality in demand, the cyclicality in advertising's sales elasticity, and the cyclicality in the per-unit profit margin. Still, more research is needed to not only extend this discussion to other marketingmix instruments (like innovation strategies, price positioning or optimal assortment composition), but also to make the recommendations more actionable and concrete. For example, when the marketing-budget should be increased, or re-allocated, how large and/or how gradual should the adjustment be?

Finally, these recommendations consider what managers should do during or after the recession. But what about before the economic crisis hits? Should forward-looking managers already prepare themselves for a potential future economic crisis, even when the timing and intensity of that crisis is still unknown? And if so, when and how (much)? More research along the lines of Rubel et al. (2011), who consider the optimal advertising spending path in light of a potential future product-harm crisis, may be useful in this respect.

\section{Conclusion}

Clearly, many questions remain that require additional research. With the current review, we have structured the existing empirical knowledge base on the impact of $\mathrm{BC}$ fluctuations on both consumers and managers. We hope this review will be helpful to other marketing researchers with a clear $\mathrm{BC}$ focus in their work. Given that the economy will surely face another downturn at some point in the future, also academic marketing research may want to take a proactive view, and already address some of these issues before the next (global or regional) crisis hits.

Acknowledgements The authors are indebted to Anirban Mukherjee and Harald van Heerde for useful comments on an earlier version of the paper. They gratefully acknowledge financial support from the Netherlands Organization for Scientific Research (NWO).

Open Access This article is distributed under the terms of the Creative Commons Attribution 4.0 International License (http:// creativecommons.org/licenses/by/4.0/), which permits unrestricted use, distribution, and reproduction in any medium, provided you give appropriate credit to the original author(s) and the source, provide a link to the Creative Commons license, and indicate if changes were made.

\section{References}

Ailawadi, K. L., Pauwels, K., \& Steenkamp, J.-B. E. M. (2008). Privatelabel use and store loyalty. Journal of Marketing, 72(6), 19-30.

Allenby, G., Jen, L., \& Leone, R. (1996). Economic trends and being trendy: the influence of consumer confidence on retail fashion sales. Journal of Business \& Economic Statistics, 14(1), 103-111.

Andersson, P., \& Mattsson, L. G. (2010). Temporality of resource adjustments in business networks during severe economic recession. Industrial Marketing Management, 39(6), 917-924.

Ang, S. H., Leong, S. M., \& Kotler, P. (2000). The Asian apocalypse: crisis marketing for consumers and businesses. Long Range Planning, 33(1), 97-119.

Axarloglou, K. (2003). The cyclicality of new product introductions. Journal of Business, 76(1), 29-48.

Barlevy, G. (2007). On the cyclicality of research and development. American Economic Review, 97(4), 1131-1164.

Baxter, M. (1994). Real exchange rates and real interest differentials: have we missed the business-cycle relationship? Journal of Monetary Economics, 33(1), 5-37.

Baxter, M., \& King, R. G. (1999). Measuring business cycles: approximate band-pass filters for economic time series. The Review of Economics and Statistics, 81(4), 575-593.

Baxter, M., \& Kouparitsas, M. A. (2005). Determinants of business cycle comovement: a robust analysis. Journal of Monetary Economics, 52(1), 113-157.

Beck, J. T., Chapman, K., \& Palmatier, R. W. (2015). Understanding relationship marketing and loyalty program effectiveness in global markets. Journal of International Marketing, 23(3), 1-21.

Beck, J. T., Harmeling, C., Bhagwat, Y., \& Henderson, C. M. (2016). Economic inequality, trust, and brand leadership. In MSI working paper series 16-109. Cambridge: MA.

Berman, J., \& Pfleeger, J. (1997). Which industries are sensitive to business cycles? Monthly Labor Review, 120(2), 19-25.

Bharadwaj, S., Clark, T., \& Kulviwat, S. (2005). Marketing, market growth, and endogenous growth theory: an inquiry into the causes of market growth. Journal of the Academy of Marketing Science, 33(3), 347-359.

Bradlow, E. (2009). Editorial-Marketing science and the financial crisis. Marketing Science, 28(2), 201. 
Bronnenberg, B. T., \& Ellickson, P. B. (2015). Adolescence and the path to maturity in global retail. The Journal of Economic Perspectives, 29(4), 113-134.

Burgess, S. M., \& Steenkamp, J.-B. E. M. (2006). Marketing renaissance: how research in emerging consumer markets advances marketing science and practice. International Journal of Research in Marketing, 23(4), 337-356.

Burns, A. F., \& Mitchell, W. C. (1946). Measuring business cycles. NBER Books.

Burnside, C. (1998). Detrending and business cycle facts: a comment. Journal of Monetary Economics, 41(3), 513-532.

Canova, F. (1998). Detrending and business cycle facts. Journal of Monetary Economics, 41(3), 475-512.

Carroll, C. D. (1992). The buffer stock theory of saving: some macroeconomic evidence. Brookings Papers on Economic Activity, 2, 61-155.

Carroll, C. D., Fuhrer, J. C., \& Wilcox, D. W. (1994). Does consumer sentiment forecast household spending? If so, why? The American Economic Review, 84(5), 1397-1408.

Cerqueira, P. A. (2013). A closer look at the world business cycle synchronization. International Economics and Economic Policy Springer, 10(3), 349-363.

Cha, W., Chintagunta, P., \& Dhar, S. (2015). Food purchases during the great recession. Booth School of Business, University of Chicago: working paper. Available at SSRN 2548758.

Christiano, L. J., \& Fitzgerald, T. J. (1998). The business cycle: it's still a puzzle. Federal Reserve Bank of Chicago Economic Perspectives, 22(4), 56-83.

Christiano, L. J., \& Fitzgerald, T. J. (2003). The band pass filter. International Economic Review, 44(2), 435-465.

Claessens, S., \& Kose, M. A. (2009). Back to basics: what is a recession? Finance and Development, 46(1), 52-53.

Clark, W. A. V., Freeman, H. E., \& Hanssens, D. M. (1984). Opportunities for revitalizing stagnant markets: an analysis of household appliances. Journal of Product Innovation Management, 1(4), 242-254.

Cleeren, K., Lamey, L., Meyer, J.-H., \& De Ruyter, K. (2015). How business cycles affect the healthcare sector: a cross-country investigation. Health Economics, 28, 14-14.

Coibion, O., Gorodnichenko, Y., \& Hong, G. H. (2015). The cyclicality of sales, regular and effective prices: business cycle and policy implications. The American Economic Review, 105(3), 993-1029.

Cook, S. (1999). Cyclicality and durability: Evidence from U.S. consumers' expenditure. Journal of Applied Economics, 11(2), 299-310.

Coulson, J. (1979). Marketing issues. Journal of Marketing, 43(4), 132-134.

Cundiff, E. W. (1975). What is the role of marketing in a recession? Journal of Marketing, 39(2), 1.

Croux, C., Forni, M., \& Reichlin, L. (2001). A measure of comovement for economic variables: Theory and empirics. The Review of Economics and Statistics, 83(2), 232-241.

Day, G. S., \& Moorman, C. (2010). Strategy from the outside in: profiting from customer value. New York: McGraw Hill.

Dekimpe, M.G., Gielens, K., Raju, J., \& Thomas, J. (2011). Strategic assortment decisions in information-intensive and turbulent environments. Journal of Retailing 87(sup 1), S17-S28.

Dekimpe, M. G., \& Hanssens, D. M. (1995). The persistence of marketing effects on sales. Marketing Science, 14(1), 1-21.

Dekimpe, M. G., Peers, Y., \& van Heerde, H. J. (2016). The impact of the business cycle on service providers: insights from international tourism. Journal of Service Research, 19(1), 22-38.

Deleersnyder, B., Dekimpe, M. G., Sarvary, M., \& Parker, P. M. (2004). Weathering tight economic times: the sales evolution of consumer durables over the business cycle. Quantitative Marketing and Economics, 2(4), 347-383.

Deleersnyder, B., Dekimpe, M. G., Steenkamp, J.-B. E. M., \& Leeflang, P. S. H. (2009). The role of national culture in advertising's sensitivity to business cycles: an investigation across continents. Journal of Marketing Research, 46(5), 623-636.
Devinney, T. M. (1990). New products over the business cycle. Journal of Product Innovation Management, 7(4), 261-273.

Dhar, T., \& Weinberg, C. B. (2016). Measurement of interactions in nonlinear marketing models: the effect of critics' ratings and consumer sentiment on movie demand. International Journal of Research in Marketing, 33(2), 392-408.

Dubé, J.-P., Hitsch, G. J., \& Rossi, P. E. (2017). Income and wealth effects on private-label demand: evidence from the great recession. Marketing Science. Forthcoming.

Dutt, P., \& Padmanabhan, V. (2011). Crisis and consumption smoothing. Marketing Science, 30(3), 491-512.

Edeling, A., \& Fischer, M. (2016). Marketing's impact on firm value: generalizations from a meta-analysis. Journal of Marketing Research, 53(4), 515-534.

Estelami, H., Lehmann, D. R., \& Holden, A. C. (2001). Macro-economic determinants of consumer price knowledge: a meta-analysis of four decades of research. International Journal of Research in Marketing, 18(4), 341-355.

Fornell, C., Rust, R. T., \& Dekimpe, M. G. (2010). The effect of customer satisfaction on consumer spending growth. Journal of Marketing Research, 47(1), 28-35.

Frösén, J., Jaakkola, M., Churakova, I., \& Tikkanen, H. (2016). Effective forms of market orientation across the business cycle: a longitudinal analysis of business-to-business firms. Industrial Marketing Management, 52, 91-99.

Gale, D. (1996). Delay and cycles. Review of Economic Studies, 63(215), 169-198.

Gicheva, D., Hastings, J., \& Villas-Boas, S. (2010). Revisiting the income effect: gasoline prices and grocery purchases. The American Economic Review, 100(2), 480-484.

Gilchrist, S., Schoenle, R., Sim, J., \& Zakrajšek, E. (2015). Inflation dynamics during the financial crisis. Finance and economics discussion series 2015-012. Washington: Board of Governors of the Federal Reserve System.

Gordon, B. R., Goldfarb, A., \& Li, Y. (2013). Does price elasticity vary with economic growth? A cross-category analysis. Journal of Marketing Research, 50(1), 4-23.

Graham, R. C., \& Frankenberger, K. D. (2011). The earnings effects of marketing communication expenditures during recessions. Journal of Advertising, 40(2), 5-24.

Green, E. J., \& Porter, R. H. (1984). Noncooperative collusion under imperfect price information. Econometrica, 52(1), 87-100.

Grewal, R., \& Tansuhaj, P. (2001). Building organizational capabilities for managing economic crisis: the role of market orientation and strategic flexibility. Journal of Marketing, 65(2), 67-80.

Gulati, R., Nohria, N., \& Wohlgezogen, F. (2010). Roaring out of recession. Harvard Business Review, 88(3), 62-69.

Haltiwanger, J. J., \& Harrington Jr., J. E. (1991). The impact of cyclical demand moments on collusive behavior. RAND Journal of Economics, 22(1), 89-106.

Hamilton, R. (2016). Consumer-based strategy: Using multiple methods to generate consumer insights that inform strategy. Journal of the Academy of Marketing Science, 44(3), 281-285.

Hanssens, D. M. (2015). Empirical generalizations about marketing impact. Cambridge MA: MSI Relevant Knowledge Series.

Hanssens, D. M. (1998). Order forecasts, retail sales, and the marketing mix for consumer durables. Journal of Forecasting, 17(34), 327-3246.

Hodrick, R. J., \& Prescott, E. C. (1997). Postwar U.S. business cycles: an empirical investigation. Journal of Money, Credit and Banking, 29(1), 1-16.

Hunneman, A., Verhoef, P. C., \& Sloot, L. M. (2015). The impact of consumer confidence on store satisfaction and share of wallet formation. Journal of Retailing, 91(3), 516-532.

Jindal, N., \& McAlister, L. (2015). The impacts of advertising assets and R\&D assets on reducing bankruptcy risk. Marketing Science, 34(4), $555-572$. 
Kamakura, W. A., \& Du, R. Y. (2012). How economic contractions and expansions affect expenditure patterns. Journal of Consumer Research, 39(2), 229-247.

Kashmiri, S., \& Mahajan, V. (2014). Beating the recession blues: Exploring the link between family ownership, strategic marketing behavior and firm performance during recessions. International Journal of Research in Marketing, 31(1), 78-93.

Katona, G. (1975). Psychological economics. New York: Elsevier Scientific Publishing Co..

Kumar, V., Leone, R. P., \& Gaskins, J. N. (1995). Aggregate and disaggregate sector forecasting using consumer confidence measures. International Journal of Forecasting, 11(3), 361-377.

Kumar, V., Umashankar, N., Kim, K. H., \& Bhagwat, Y. (2014). Assessing the influence of economic and customer experience factors on service purchase behaviors. Marketing Science, 33(5), 673-692.

Lamey, L. (2014). Hard economic times: a dream for discounters. European Journal of Marketing, 48(3/4), 641-656.

Lamey, L., Deleersnyder, B., Dekimpe, M. G., \& Steenkamp, J.-B. E. M. (2007). How business cycles contribute to private-label success: evidence from the United States and Europe. Journal of Marketing, 71(1), 1-15.

Lamey, L., Deleersnyder, B., Steenkamp, J.-B. E. M., \& Dekimpe, M. G. (2012). The effect of business cycle fluctuations on private-label share: what has marketing conduct got to do with it? Journal of Marketing, 76(1), 1-19.

Lee, H. L., Padmanabhan, V., \& Whang, S. (1997). The bullwhip effect in supply chains. Sloan Management Review, 38(3), 93-102.

Lee, H. L., Padmanabhan, V., \& Whang, S. (2004). Information distortion in a supply chain: the bullwhip effect. Management Science 50(12_supplement), 1875-1886.

Lilien, G. L. (2016). The B2B knowledge gap. International Journal of Research in Marketing, Forthcoming.

Ma, Y., Ailawadi, K. L., Gauri, D. K., \& Grewal, D. (2011). An empirical investigation of the impact of gasoline prices on grocery shopping behavior. Journal of Marketing, 75(2), 18-35.

MacInnis, D. (2011). A framework for conceptual contributions in marketing. Journal of Marketing, 75(4), 136-154.

Marn, M. V., Roegner, E. V., \& Zawada, C. C. (2003). The power of pricing. The McKinsey Quarterly, 1, 26-40.

Mascarenhas, B., \& Aaker, D. A. (1989). Strategy over the business cycle. Strategic Management Journal, 10(3), 199-210.

Millet, K., Lamey, L., \& Van den Bergh, B. (2012). Avoiding negative vs. achieving positive outcomes in hard and prosperous economic times. Organizational Behavior and Human Decision Processes, $117(2), 275-284$.

Moorman, C., \& Day, G. S. (2016). Organizing for marketing excellence. Journal of Marketing, 80(6), 6-35.

Mukherjee, A., \& Bonfrer, A. (2015). Does economic growth lead to consumers purchasing more energy efficient appliances? Paper presented at the 2015 EMAC Conference. Leuven, Belgium.

Mukherjee, A., \& Xiao, P. (2016). Dalal street blues: the economic environment and the demand for Bollywood movies. Paper presented at the China-India Insights Conference, London, U.K.

Nooteboom, B., Berger, H., \& Noorderhaven, N. G. (1997). Effect of trust and governance on relational risk. Academy of Management Journal, 40(2), 308-338.

Ou, Y-C., de Vries, L., Wiesel, T., \& Verhoef, P.C. (2014). The role of consumer confidence in creating customer loyalty. Journal of Service Research, 17(3), 339-354

Özturan, P., Özsomer, A., \& Pieters, R. (2014). The role of market orientation in advertising spending during economic collapse: the case of Turkey in 2001. Journal of Marketing Research, 51(2), 139-152.

Peers, Y., van Heerde, H. J., \& Dekimpe, M. G. (2017). Marketing budget allocation across countries: the role of international business cycles. Marketing Science, Forthcoming.
Quelch, J. A., \& Jocz, K. E. (2009). How to market in a downturn. Harvard Business Review, 87(4), 52-62.

Randles, R. H., Fligner, M. A., Policello II, G. E., \& Wolfe, D. A. (1980). An asymptotically distribution-free test for symmetry versus asymmetry. Journal of the American Statistical Association, 75(369), 168-172.

Reibstein, D. (2011). How sustainable is Groupon's business model? Knowledege@Wharton, May 25.

Rotemberg, J. J., \& Saloner, G. (1986). The supergame-theoretic model of price wars during booms. The American Economic Review, 76(3), 390- 407.

Rubel, O., Naik, P. A., \& Srinivasan, S. (2011). Optimal advertising when envisioning a product-harm crisis. Marketing Science, 30(6), 10481065.

Schöler, L., Skiera, B., \& Tellis, G. J. (2014). Stock market returns to financial innovations before and during the financial crisis in the United States and Europe. The Journal of Product Innovation Management, 31(5), 973-986.

Sethuraman, R., Tellis, G. J., \& Briesch, R. A. (2011). How well does advertising work? Generalizations from meta-analysis of brand advertising elasticities. Journal of Marketing Research, 48(3), 457471.

Sichel, D. E. (1993). Business cycle asymmetry: A deeper look. Economic Inquiry, 31(2), 224-236.

Shiskin, J. (1974). The changing business cycle. New York Times, (December 12), 222

Srinivasan, R., Lilien, G. L., \& Sridhar, S. (2011). Should firms spend more on research and development and advertising during recessions? Journal of Marketing, 75(3), 49-65.

Srinivasan, R., Rangaswamy, A., \& Lilien, G. L. (2005). Turning adversity into advantage: does proactive marketing during a recession pay off? International Journal of Research in Marketing, 22(2), 109-125.

Steenkamp, J.-B. E. M. (2005). Moving out of the U.S. silo: a call to arms for conducting international marketing research. Journal of Marketing, 69(4), 6-8.

Steenkamp, J.-B. E. M., \& Geyskens, I. (2014). Manufacturer and retailer strategies to impact store brand share: global integration, local adaptation, and worldwide learning. Marketing Science, 33(1), 6-26.

Steenkamp, J.-B. E. M., \& Fang, E. (2011). The impact of economic contractions on the effectiveness of R\&D and advertising: evidence from U.S. companies spanning three decades. Marketing Science, 30(4), 628-645.

Stock, J. H., \& Watson, M. W. (1999). Business cycle fluctuations in U.S. macroeconomic time series. In J. Taylor \& M. Woodford (Eds.), Handbook of macroeconomics (pp. 3-64). Amsterdam: Elsevier Science.

Sudhir, K., Chintagunta, P. K., \& Kadiyali, V. (2005). Time-varying competition. Marketing Science, 24(1), 96-109.

Talay, M. B., Pauwels, K., \& Seggie, S. H. (2012). To launch or not to launch in recessions? Evidence from over 60 years of the automobile industry. MSI working paper series 12-109, Cambridge MA.

Tavassoli, N. T., Sorescu, A., \& Chandy, R. (2014). Employee-based brand equity: why firms with strong brands pay their executives less. Journal of Marketing Research, 51(6), 676-690.

Tellis, G. J., \& Tellis, K. (2009). Research on advertising in a recession. Journal of Advertising Research, 49(3), 304-327.

ter Braak, A., Geyskens, I., \& Dekimpe, M. G. (2014). Taking private labels upmarket: empirical generalizations on category drivers of premium private label introductions. Journal of Retailing, 90(2), 125-140.

The Economist (2009). The game has changed. The recession has spelt disaster for most brands of packaged goods, but not all. August 20 . (accessed July 25, 2016), [available at http://www.economist.com/ node/14259150].

The Wall Street Journal (2009). What management strategy should I use in an economic downturn? April 7, (accessed July 25, 2016), [available at http://guides.wsj.com/management/strategy/whatmanagement-strategy-should-i-use-in-an-economic-downturn/]. 
Tuli, K., Mukherjee, A., \& Dekimpe, M. G. (2012). On the value relevance of retailer advertising spending and same-store sales growth. Journal of Retailing, 88(4), 447-461.

Tversky, A., \& Kahneman, D. (1991). Loss aversion in riskless choice: a reference-dependent model. Quarterly Journal of Economics, 106(4), 1039-1061.

van Heerde, H. J., Gijsenberg, M., Dekimpe, M. G., \& Steenkamp, J.-B. E. M. (2013). Price and advertising effectiveness over the business cycle. Journal of Marketing Research, 50(2), 177-193.

Verbrugge, R. J. (1997). Investigating cyclical asymmetries. Studies in Nonlinear Dynamics and Econometrics, 2(1), 15-22.

Whetten, D. A. (1989). What constitutes a theoretical contribution? The Academy of Management Review, 14(4), 490-495.
Yang, C. Y. (1964). Variations in the cyclical behavior of advertising. Journal of Marketing, 28(2), 25-30.

Yeung, M. C. H., Ramasamy, B., Chen, J., \& Paliwoda, S. (2013). Customer satisfaction and consumer expenditure in selected European countries. International Journal of Research in Marketing, 30(4), 406-416.

Zarnowitz, V. (1985). Recent work on business cycles in historical perspective: review of theories and evidence. Journal of Economic Literature, 23(2), 523-580.

Zeithaml, V., Parasuraman, A., \& Berry, L. L. (1985). Problems and strategies in services marketing. Journal of Marketing, 49(2), 33-46. 